\title{
West African convection regimes and their predictability from submonthly forecasts
}

\author{
N. Vigaud ${ }^{1}\left[\right.$ - A. Giannini ${ }^{1}$
}

Received: 21 March 2018 / Accepted: 30 November 2018

(c) Springer-Verlag GmbH Germany, part of Springer Nature 2018

\begin{abstract}
Recurrent convection regimes are identified during the extended West African Monsoon (WAM) season (May-Nov) using a $k$ - means clustering of 1980-2013 NOAA daily Outgoing Longwave Radiation (OLR), and are well reproduced in 1996-2015 ECMWF week-1 reforecasts despite systematic biases. One regime of broad drying across the Sahel in the early (May-Jun) and late (Oct) WAM is of particular interest regarding the prediction of onset date. This regime is associated with an anticyclonic cell along the Atlantic coast of West Africa leading to a weakened monsoon flow and subsiding anomalies across the Sahel. Teleconnections of this regime with the Indian monsoon sector are identified through modulations of the Walker circulation alongside relationships to MJO phase 3 more than 10 days in advance, when convection is enhanced over the Indian Ocean. Other regimes are associated with westward propagating anomalous convective cells along two distinct wave trains at $15^{\circ} \mathrm{N}$ and $24^{\circ} \mathrm{N}$ during the core (Jul-Sep) and late (Oct-Nov) WAM, respectively, and translate into wet anomalies transiting across the Sahel. A regime of broad Sahel wetting in the core WAM, more frequent since the 1990s, is related to global SST warming, agreeing with the observed recovery of Sahel rainfall. ECMWF skill in forecasting regime sequences decreases from week-1 to -4 leads, except in the case of the above-mentioned regime associated with early season dry spells, translating into the potential for skillful WAM onset date predictions. Our analysis suggests that sources of predictability include relationships to the MJO and the Indian monsoon sector, which need to be further examined to benefit subseasonal forecasting efforts in West Africa, and ultimately agricultural planning and food security across the Sahel.
\end{abstract}

\section{Introduction}

Most of West Africa relies on rainfed agriculture and local societies are thus most vulnerable to climatic variations including intra-seasonal characteristics of the rainy season. Subseasonal-to-seasonal (S2S) forecasting (lead time between 2 weeks and 2 months) is a new area of climate prediction that occupies the range between medium range weather forecasts (up to 2 weeks) and seasonal climate prediction (from 3 to 6 months) and is currently the focus of intense research efforts, amongst which the joint World Weather Research Program (WWRP)—World Climate Research Program (WCRP) S2S prediction project (World Meteorological Organization 2013). The recently published S2S database (Vitart et al. 2017), consisting of submonthly

N. Vigaud

nicolas.vigaud@gmail.com

1 International Research Institute for Climate and Society, Earth Institute at Columbia University, Palisades, New York, USA forecasts from multiple ensemble prediction systems, offers an unprecedented opportunity to further examine the skill of extended range forecasts (i.e., 10-30 days time range) in predicting climate variability on intra-seasonal time-scales. In particular, the objectives of the S2S Monsoon and Africa sub-projects (World Meteorological Organization 2013) both include the assessment of forecasts performance for monsoon onset dates with the aim to ultimately develop and operationalize in real-time, intra-seasonal forecast products relevant to agriculture, water resources and public health. West African rainfall largely results from the land-sea temperature contrast leading to a southwesterly monsoonal flow that feeds moisture from the Atlantic into deep convection processes within the seasonal rainbelt. After pre-onset and onset phases in April and June respectively, when the rainbelt over the Guinea Gulf suddenly extends northwards, the West African summer rainy season starts with an abrupt shift of the rainfall maximum from $5^{\circ} \mathrm{N}$ to $10^{\circ} \mathrm{N}$ at the end of June and prevails during July-September (Sultan and Janicot 2000, 2003; Le Barbé et al. 2003; Ramel et al. 2006). Given the complexity of dynamical features of subseasonal 
variability, most notably mesoscale convective systems (MCS), African Easterly Waves (AEWs), and the African Easterly Jet (AEJ), a weather typing approach is developed to identify recurrent daily convection regimes and their potential predictability from submonthly forecasts, subsequently illustrated for onset date prediction.

The West African Monsoon (WAM) activity is sensitive to both local forcing and remote influences, which modulate dry and wet spell occurrences at interannual (Lebel et al. 2003) and intra-seasonal (Sultan et al. 2003) time-scales. At interannual time-scales, West African rainfall is influenced by large-scale teleconnections with SSTs in the Pacific, Atlantic and Indian Ocean (Rowell 2013). For instance, relationships to El Niño-Southern Oscillation (ENSO) have been marked by contrasting periods of strong and weak correlation (Janicot et al. 2001). However, when removing the long term variability, ENSO impact is clearly seen over the region (Giannini et al. 2003), with El Niño episodes clearly associated with significant drying after the 1970s. In addition, the Gulf of Guinea modulates the WAM circulation through moist static energy content at lower tropospheric levels (Eltahir and Gong 1996; Joly and Voldoire 2009) and WAM precipitation tends to be reduced during Atlantic Niños or positive phases of the Atlantic Equatorial Mode (Losada et al. 2010).

Precipitation and convection within the WAM exhibit primary modulations at 10-25 and 25-60 days (Sultan et al. 2003) and three main modes of convection variability are identified at these frequency bands. The first 10-25 day mode, dubbed the "Quasi-Biweekly Zonal Dipole" or QBZD (Mounier et al. 2008), is characterized by eastward propagating convection anomalies between the Gulf of Guinea coast/Central Africa and the western tropical Atlantic. This mode is primarily controlled by equatorial disturbances transiting eastwards. Another 10-25 day mode, the "Sahel mode" (Sultan et al. 2003; Janicot et al. 2010), is related to a westward-propagating anomalous circulation in the midtroposphere, which is maintained by land-atmosphere and radiation-atmosphere interactions (Taylor 2008; Taylor et al. 2011), internal atmospheric dynamics (Lavender and Matthews 2009) and coupled equatorial Rossby waves (Janicot et al. 2010). Lastly, a mode related to the Madden-Julian Oscillation (MJO) and prevailing in the 25-90 days band, the "African MJO" mode (Matthews 2004; Janicot et al. 2009), is characterized by westward-propagating convection anomalies linked to MJO activity over the Indian-West Pacific sector predominantly through dry Rossby waves and their interactions with equatorial dry Kelvin waves over Africa (Matthews 2004). The latter are generated by negative MJO-induced sea surface temperature (SST) anomalies within the equatorial warm pool region (Lavender and Matthews 2009) and meet about 20 days later over Africa, where they enhance monsoon convection. Interestingly, the three convective modes cited above have higher predictability individually (Sultan et al. 2009), as part of teleconnections with the Indian monsoon and extra-tropics (Vizy and Cook 2009; Chauvin et al. 2010).

At synoptic time-scales, a sub-population of MCS, the organized convective systems representing only $12 \%$ of the total number of MCS, is the major source of rainfall over the Sahel (Mathon et al. 2002). The decrease in the number of these rain producing convective systems is the main cause for rainfall deficit during dry spells (Le Barbé et al. 2003; Lebel et al. 2003). However, associated mechanisms are not yet fully understood, neither has the capacity of atmospheric predictors from GCM forecasts been examined for the 10-30 days range in regards to monsoon onset (Fontaine and Louvet 2006). Vigaud et al. (2017) recently found skill in week 3-4 precipitation tercile outlooks from a multi-model ensemble of S2S forecasts over the WAM with potentially higher skill for the onset phases, as also evidenced by Bombardi et al. (2017). In this perspective, the goal of this study is to diagnose subseasonal convection variability and predictability over West Africa by clustering daily Outgoing Longwave Radiation (OLR) from observations and reforecasts from the European Centre for Medium-Range Weather Forecasts (ECMWF) in May-November. The article is outlined as follows. Data and methods are presented in Sect. 2. Results from the cluster analysis are discussed in Sect. 3 in relationship to rainfall, the atmospheric circulation, the MJO and large-scale SSTs. Regime predictability is examined from ECMWF week-1 to week-4 reforecasts in Sect. 4 before presenting an application for WAM onset prediction. Conclusions are synthesized in Sect. 5.

\section{Data and methods}

\subsection{Observation and dynamical model predictions}

Tropical convection is examined over West Africa between $20^{\circ} \mathrm{E}$ and $20^{\circ} \mathrm{W}$ from May to November using $2.5^{\circ} \times 2.5^{\circ}$ gridded daily OLR produced by the National Oceanic and Atmospheric Administration (NOAA) available from 1980 to present (Liebmann and Smith 1996). While the coarse spatial resolution of OLR does not capture individual mesoscale convective systems, it is their synoptic scale organization that is of interest in this paper.

Gridded daily rainfall estimates from the Climate Hazards group InfraRed Precipitation with Station dataset (CHIRPS) developed at the University of California at Santa Barbara Climate Hazards Group (CHG) in collaboration with the U.S. Geological Survey Earth Resources Observation and Science (EROS) center (Funk et al. 2014) are here utilized. These data are at $0.05^{\circ}$ latitude-longitude resolution. Also including satellite information, CHIRPS data is one of the 
few available datasets covering the whole continental region at daily time-scales that has data back to the 1980s, and which has been validated in recent studies including for the tropics (Funk et al. 2015). NOAA OLR comes from polar orbiting satellites, while CHIRPS rainfall estimates contain remote sensing information from geostationary satellites. Thus, the two products may be considered as independent (Vigaud et al. 2016). Since CHIRPS covers land areas only, the Tropical Rainfall Measuring Mission (TRMM) 3B42 v7 daily satellite estimates at a quarter degree spatial resolution (Huffman et al. 2010) are also considered for the 1998-2013 period, to relate anomalies over land with anomalous largescale patterns. The Global Precipitation Climatology Project (GPCP) version 1.2 (Huffman et al. 2001; Huffman and Bolvin 2012) daily precipitation estimates on a $1^{\circ}$ grid from 1998 to 2013, are used alongside those from CHIRPS and TRMM to compute the WAM onset index (WAMOI) as the zonally averaged difference over $\left[10^{\circ} \mathrm{W}-10^{\circ} \mathrm{E}\right]$ between precipitation averaged over $\left[7.5-20^{\circ} \mathrm{N}\right]$ and $\left[0-7.5^{\circ} \mathrm{N}\right]$ (Fontaine and Louvet 2006) standardized after 15-day smoothing, the onset corresponding to the first day of a 20-day (or longer) period with positive WAMOIs. Tropical Application of Meteorology Using Satellite Data and Ground-Based Observations (TAMSAT) daily precipitation estimates, based on high-resolution thermal-infrared observations (Maidment et al. 2017), merged with station rainfall data and available at $4 \mathrm{~km}$ spatial resolution (Dinku et al. 2014) are also used to compute local onset dates. At each grid point, these are defined as the date when cumulative rainfall of at least $20 \mathrm{~mm}$ is obtained in 1-to-3 consecutive days and without any dry spell exceeding 20 days during the following 30 days. This is consistent with the definition used at the Centre Regional de Formation et d'Application en Agrométéorologie et Hydrologie Opérationnelle (AGRHYMET) and the PREvisions climatiques Saisonnière en Afrique SoudanoSahélienne (PRESASS) forums.

Daily geopotentials, winds and omega vertical velocities from the NCEP-DOE II reanalysis (NCEP2 in the following), produced jointly by NCEP and the US Department of Energy (DOE), at $2.5^{\circ} \times 2.5^{\circ}$ horizontal resolution (Kanamitsu et al. 2002), are used to investigate key atmospheric circulation features including surface conditions, AEWs activity and upper-level westerly waves.

The relationships between convection regimes identified through clustering of daily OLR (Sect. 2.2), and SSTs in the different oceanic basins is assessed using the NOAA Optimum Interpolation SST version 2 (OISST) dataset consisting of daily values at a quarter of a degree (Reynolds et al. 2007), which were aggregated for May-Nov seasons from 1982 to 2014.

To investigate the reproducibility of observed regimes by models from the S2S database (World Meteorological Organization 2013), daily OLR from ECMWF week-1 (i.e., the period $[d+1, d+7]$ for a forecast issued on day $d$ ) 11-member reforecasts. ECMWF reforecasts are generated on the fly twice a week (11 members every Monday and Thursday), and those with Thursday starts from May to November 2016 (i.e., May 2-Nov 28 start dates) are used in the following over the 1996-2015 period. Reforecasts produced at $16 \mathrm{~km}$ spatial resolution up to day 10 and at 32 $\mathrm{km}$ thereafter (i.e., Tco639/319 truncations) are available from the S2S database (Vitart et al. 2017), where they are archived at 1.5-degree spatial resolution. Regime predictability is then examined from week- 1 to week-4 reforecasts (i.e., periods from $[d+1, d+7]$ to $[d+22, d+28]$ ) in Sect. 4 .

\subsection{Dynamical clustering approach}

Subseasonal convection activity is first examined from daily NOAA OLR for the May-Nov season over the domain $\left[0-25^{\circ} \mathrm{N} ; 20^{\circ} \mathrm{E}-20^{\circ} \mathrm{W}\right]$ centered on West Africa. The seasonal cycle was not removed from OLR prior to the analysis so as to retain synoptic weather and its seasonality. To reduce the dimensionality of the problem and to ensure linear independence between input variables, an empirical orthogonal function analysis is apriori performed on the data correlation matrix. The first 11 principal components (PCs), explaining $70 \%$ of the variance based on the covariance matrix are retained and are input into an objective classification through $k-$ means clustering (Michelangeli et al. 1995; Cheng and Wallace 2003). For week-1, the different ensemble members are expected to be close to the ensemble mean solution, and the same methodology is applied to ECMWF week-1 ensemble mean daily OLR fields aggregated from weekly starts issued in May-Nov over 1996-2015 similarly to other studies (Vigaud et al. 2018). When pre-processing ECMWF week-1 OLR, 13 PCs explaining about $81 \%$ of the variance of the 11-member ensemble mean reforecasts are retained based on the covariance matrix. For each dataset separately, the Euclidean distance is then used to measure similarities between daily OLR patterns and a given regime. The robustness of regime partitions is measured by a classifiability index (Cheng and Wallace 2003) and compared to confidence limits from a red-noise test applied to Markovgenerated red-noise data (Michelangeli et al. 1995; Moron and Plaut 2003; Vigaud et al. 2012, 2016; Vigaud and Robertson 2017).

\subsection{Significance testing}

Results from composites related to each daily OLR regime are tested for statistical significance using a two-tailed Student's t-test, comparing the means of the total fields from all days belonging to a regime versus the May-Nov mean over the 34-year study period. The significance of correlations between yearly regime frequencies and seasonal SSTs 
in May-Nov is determined using a resampling Monte Carlo bootstrap test based on 1000 random permutations (Livezey and Chen 1983). Non-significant scores are systematically masked in the subsequent plots. Monte Carlo simulations are also used in Sect. 3.3 to test the significance of regime fractions per MJO phases based on many random subsets of NOAA regimes (i.e., 1000) drawn from the entire pool of reanalyses during the May-Nov period, from which the 95th percentile counts are compared to those of MJO phase samples.

\subsection{Skill metrics}

In Sect. 4, the skill of ECMWF reforecasts at week-1 to -4 leads is examined in the convection regimes subspace by projecting daily OLR ensemble mean reforecasts onto the seven observed regime patterns. Forecast skill is measured for each regime separately with performance diagrams (Roebber 2009) which allow to represent multiple measures of dichotomous forecast quality including the success ratio ( $\mathrm{SR}$, based on the false alarm ratio $\mathrm{FAR}$ as $\mathrm{SR}=1-\mathrm{FAR}$ ), the probability of detection (POD), bias, and critical success index (CSI), based on the $2 \times 2$ contingency tables formed by daily observed/forecasted regime occurrences for all starts of the May-Nov 1996-2013 period.

\section{Recurrent convection regimes over West Africa}

Applying $k-$ means clustering to daily NOAA OLR (1980-2013) over the domain $\left[0-25^{\circ} \mathrm{N} ; 20^{\circ} \mathrm{E}-20^{\circ} \mathrm{W}\right]$ leads to the clustering index shown in Fig. 1, which exhibits a significant peak for $k=7$ and larger values. The 7-cluster partition is the most compact and significant solution thus selected for analysis.

\subsection{Mean patterns, transitions and seasonality}

Figure 2 displays each NOAA regime's daily OLR anomalies with respect to the mean seasonal cycle smoothed with a 5-day running mean, obtained by compositing over all days assigned to each regime. The 7-cluster partition consists of one "dry" (2) and two "wet" (1 and 7) regimes for which convection is respectively suppressed and enhanced, and four propagating regimes characterized by alternating positive/negative OLR anomalies typical of anomalous convective cells transiting across West Africa along $15^{\circ} \mathrm{N}$ (regimes 3 and 5) and $24^{\circ} \mathrm{N}$ (regimes 4 and 6).

The 7-regime partition is well reproduced in ECMWF week-1 ensemble mean reforecasts, as shown by OLR anomalies constructed by subtracting the week-1 averaged forecast 1996-2015 climatology smoothed using a 5-day
Fig. 1 Classifiability index as a function of the number of regimes $k$ (boxes). The levels of significance at 5 and $10 \%$ (solid and dashed) are computed according to a first-order Markov process

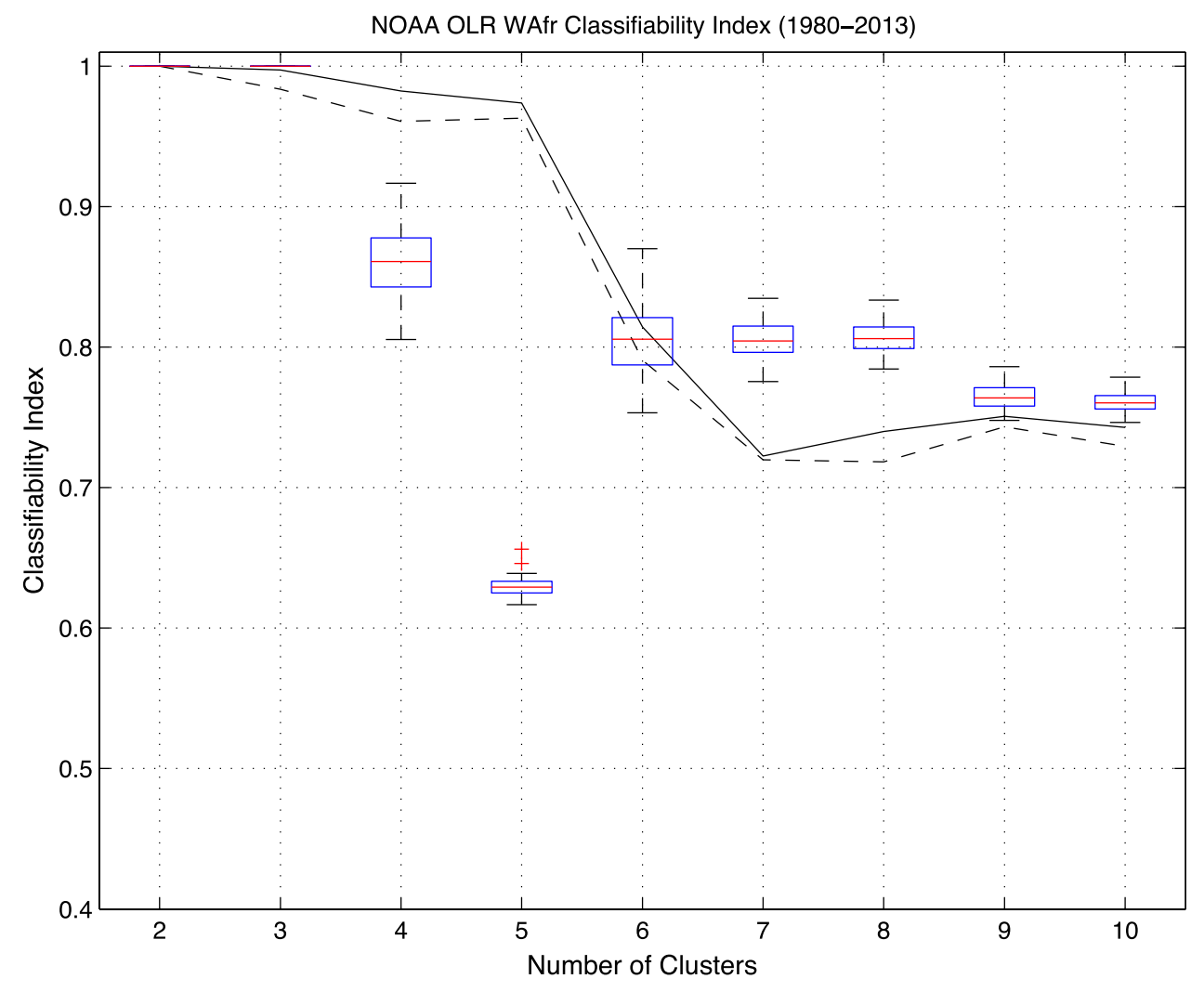


(a) NOAA CLASS1

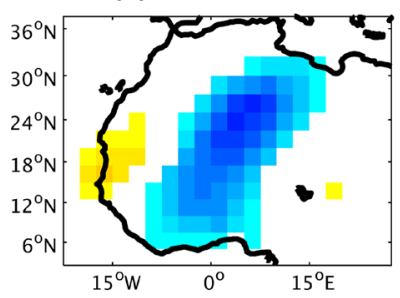

(c) NOAA CLASS3

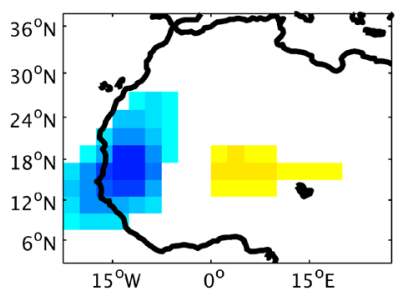

(e) NOAA CLASS5

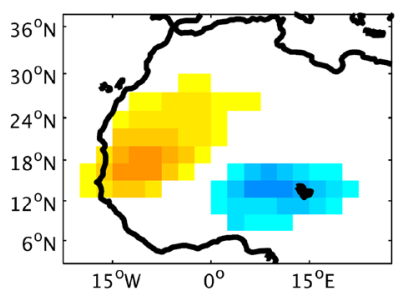

(g) NOAA CLASS7

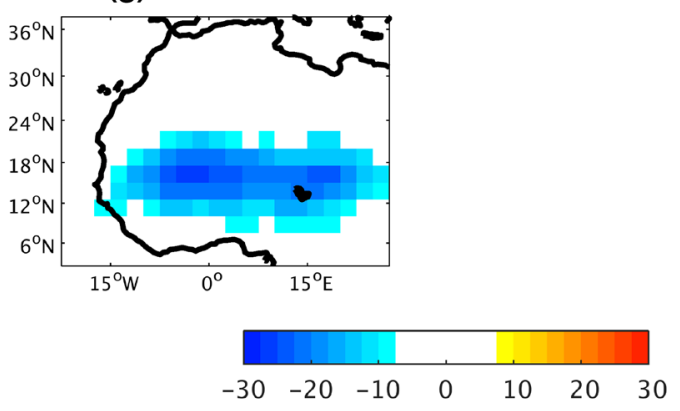

Fig. 2 Mean NOAA OLR anomalies (in $\mathrm{W} / \mathrm{m}^{2}$ ) for each regime during the May-Nov season over the 1980-2013 period. All anomalies presented are significant at $5 \%$ level of Student's t-test

running mean (Fig. 3a-g). Maximum differences of the same sign of the corresponding anomalies (Fig. 3h-n) suggest differences in magnitude, but not in the overall pattern structures for most regimes, except for regime 1 , for which highest negative loadings along the Guinean coast in ECMWF contrast with the southwest-northeast elongated anomalies in NOAA. Compared to NOAA, regime 2 is related to broader drying across Guinean regions and meridionally alternating positive/negative differences for regimes 4-6 reflect a southward shift of anomalies in ECMWF. These results suggest potential differences between observed dynamics and those simulated by the model. However, greater similarities for most regimes are evidence of the fidelity of the model's deterministic forecasts in the 7-day range. In addition, the regimes obtained by clustering ECMWF week-1 output for a single ensemble member are significantly correlated (not shown) to those obtained from the ensemble mean, except for regime 3 . The outcome potentially reflects the model's internal variability, with patterns of similar structure but anomalies of lower amplitudes for a single member compared to the ensemble mean, and suggests that, beyond being the best estimate of the model's forecast, the ensemble mean also provides a more robust representation of recurring convection patterns in the model.

Transitions between regimes are illustrated in Table 1 . Highest scores are found along the diagonal suggesting the persistence of regimes at daily time-scale, while particular sequences are favored, as shown by significant transition probabilities compared to chance. Amongst them, regime 5 prefentially follows regime 3 and precedes regime 7, while regimes 4 and 6 alternate. Regimes 3-5 and 4-6 thus reflect the westward transit of anomalous convective cells along two distinct wave trains at $15^{\circ} \mathrm{N}$ and $24^{\circ} \mathrm{N}$ spaced similarly as the main AEWs tracks (Diedhiou et al. 1999). By comparison, ECMWF overestimates the occurrence of regimes 1,4 and 7, while underpredicting those of regimes 2,3 and 5 (Table 2). In ECMWF, regimes 3 and 7 preferentially follow each other and the same is true of regimes 4 and 5. Nevertheless, transition probabilities are small in the model. The prevalence of regimes 3-7 transitions in the model contrasts with those from regimes 3-5 and 5-7 favored in the observations and could suggest different dynamics, while the similar structures of the large-scale OLR patterns typical of these regimes indicate that such differences could also be attributed in part to the shorter ECMWF period.

The number of occurrences of NOAA regimes over the 1980-2013 period is broken by month in Fig. 4a. Regimes 1 and 2 are most frequent at the beginning (May-Jun) and end (Oct) of the season with maximum number of occurrences in May, when the seasonal rainbelt is at its southernmost position, which agrees with rainfall seasonality in the case of regime 2 associated with suppressed convection. Regimes 3, 5 and 7 occur mainly during the core WAM season (Jul-Sep), when the seasonal rainbelt migrates northwards. The pattern of convection anomalies associated with these regimes, propagating westwards along $15^{\circ} \mathrm{N}$, indicates an association with the AEJ and most particularly 3-5 days AEWs (Diedhiou et al. 1999) developing within the core jet locations $\left(5-15^{\circ} \mathrm{N}\right)$. In contrast, regimes 4 and 6 are most frequent in Oct-Nov, when the seasonal rainbelt retreats southwards and the permanent anticylones potentially exert more influence on zonal wind crucial to the initiation and maintenance of the 6-9 days waves (Diedhiou et al. 1999). Overall, regime seasonalities are well reproduced by ECMWF at week-1 lead (Fig. 4c) despite differences in magnitude that could be 
(a) ECMWF CLASS1

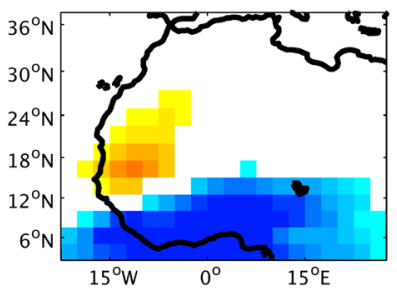

(c) ECMWF CLASS3

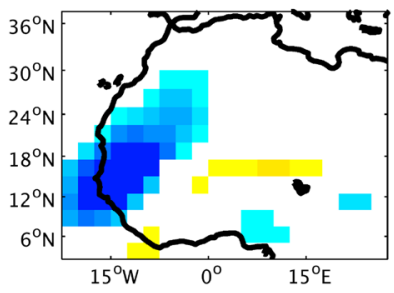

(e) ECMWF CLASS5

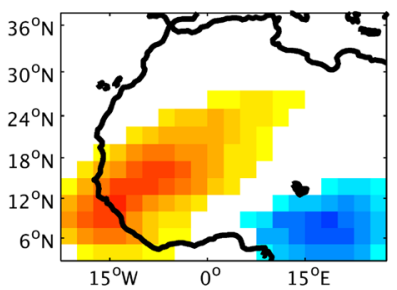

(g) ECMWF CLASS7

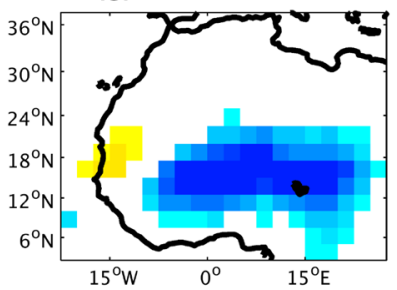

\begin{tabular}{lllllll}
\hline & & & & &. & \\
-30 & -20 & -10 & 0 & 10 & 20 & 30
\end{tabular}

Fig. 3 Mean ECMWF week-1 OLR anomalies (in $\mathrm{W} / \mathrm{m}^{2}$ ) for each regime during the May-Nov season over the 1996-2015 (a-g) and differences (red/blue contours correspond to positive/negative anomalies (h) ECMWF-NOAA CLASS1

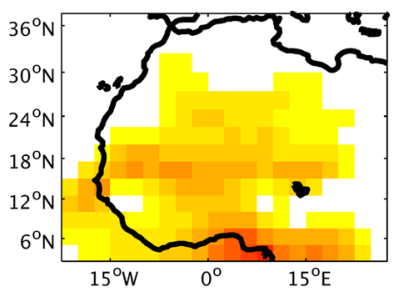

(d) ECMWF CLASS4

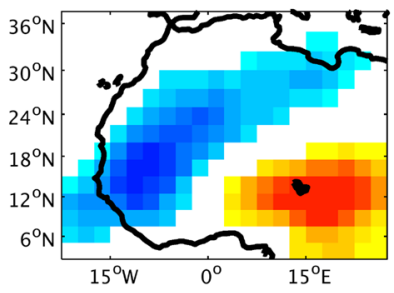

(f) ECMWF CLASS6

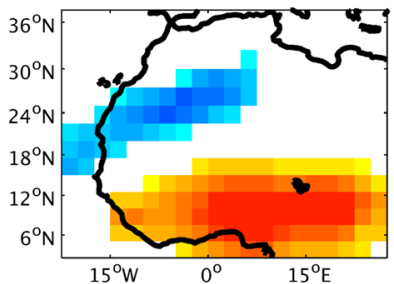

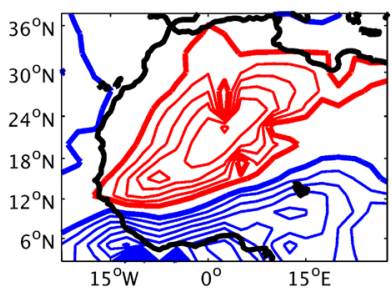

(j) ECMWF-NOAA CLASS3

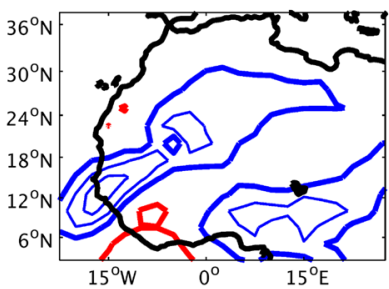

(I) ECMWF-NOAA CLASS5

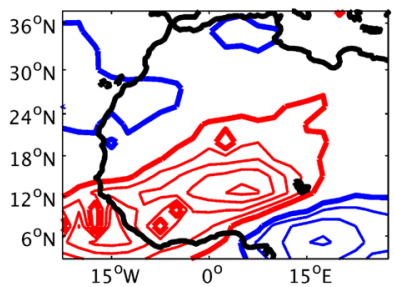

(n) ECMWF-NOAA CLASS7

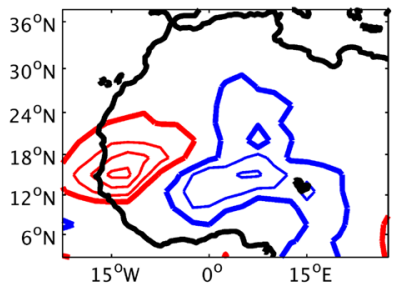

(i) ECMWF-NOAA CLASS2

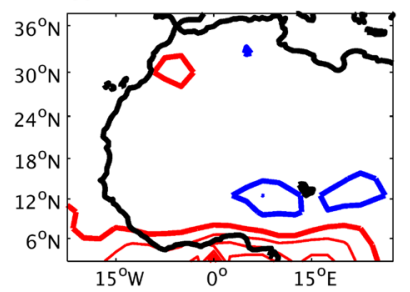

(k) ECMWF-NOAA CLASS4

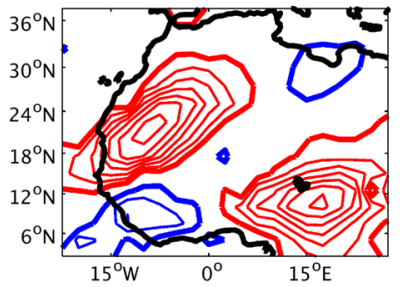

(m) ECMWF-NOAA CLASS6

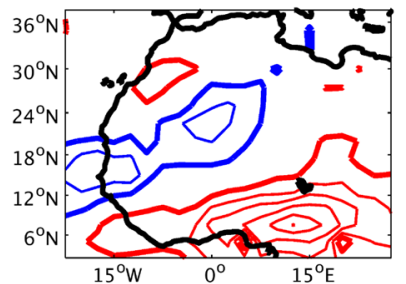

starting at $\pm 10 \mathrm{~W} / \mathrm{m}^{2}$ and every $\pm 5 \mathrm{~W} / \mathrm{m}^{2}$ ) with those from NOAA $(\mathbf{h}-\mathbf{n})$. All anomalies and differences are significant at $5 \%$ level of Student's t-test

Table 1 Contingency tables of daily transitions between the seven daily NOAA OLR classes (1980-2103)

\begin{tabular}{lcccccccc}
\hline To & Class 1 & Class 2 & Class 3 & Class 4 & Class 5 & Class 6 & Class 7 & Total \\
\hline From & & & & & & & & \\
Class 1 & $390^{*}(52)$ & $84(11)$ & $96(13)$ & $38(5)$ & $50(7)$ & $73(9)$ & $23(3)$ & $754(10)$ \\
Class 2 & $68(5)$ & $850^{*}(64)$ & $132(10)$ & $2(0)$ & $194(14)$ & $79(6)$ & $8(1)$ & $1333(18)$ \\
Class 3 & $45(4)$ & $157(14)$ & $461^{*}(40)$ & $37(3)$ & $262^{*}(24)$ & $33(3)$ & $141(12)$ & $1136(16)$ \\
Class 4 & $35(8)$ & $3(1)$ & $33(7)$ & $273^{*}(62)$ & $0(0)$ & $93 *(21)$ & $4(1)$ & $441(6)$ \\
Class 5 & $101(7)$ & $152(11)$ & $183(13)$ & $0(0)$ & $687 *(50)$ & $6(1)$ & $254 *(18)$ & $1383(19)$ \\
Class 6 & $61(7)$ & $73(8)$ & $35(4)$ & $90^{*}(10)$ & $10(1)$ & $638^{*}(70)$ & $2(0)$ & $909(13)$ \\
Class 7 & $47(4)$ & $3(0)$ & $193(15)$ & $11(1)$ & $176(14)$ & $2(0)$ & $854 *(66)$ & $1286(18)$ \\
\hline
\end{tabular}

In parentheses are indicated the respective transition probabilities (in \%) obtained by dividing separate class counts by the sum of the columns of each row

Stars (*) indicate significance at $0.1 \%$ level of $\chi^{2}$ test 
Table 2 Similar to Table 1 but for daily ECMWF week-1 reforecasts (1996-2015)

\begin{tabular}{lcccccccc}
\hline To & Class 1 & Class 2 & Class 3 & Class 4 & Class 5 & Class 6 & Class 7 & Total \\
\hline From & & & & & & & & \\
Class 1 & $342^{*}(76)$ & $29(5)$ & $16(3)$ & $32(9)$ & $23(5)$ & $0(0)$ & $11(1)$ & $453(12)$ \\
Class 2 & $(4) 17$ & $411^{*}(66)$ & $61(11)$ & $13(3)$ & $28(6)$ & $1(0)$ & $94(10)$ & $625(16)$ \\
Class 3 & $19(4)$ & $72(11)$ & $294 *(53)$ & $14(4)$ & $22(5)$ & $0(0)$ & $133 *(14)$ & $554(14)$ \\
Class 4 & $28(6)$ & $16(3)$ & $7(1)$ & $245^{*}(65)$ & $47 *(10)$ & $42(8)$ & $0(0)$ & $385(10)$ \\
Class 5 & $33(5)$ & $34(7)$ & $8(1)$ & $50^{*}(13)$ & $308^{*}(66)$ & $31(6)$ & $5(1)$ & $469(12)$ \\
Class 6 & $0(0)$ & $0(0)$ & $0(0)$ & $22(6)$ & $37(8)$ & $439 *(86)$ & $0(0)$ & $498(13)$ \\
Class 7 & $9(2)$ & $62(10)$ & $168^{*}(30)$ & $3(1)$ & $1(0)$ & $0(0)$ & $673 *(73)$ & $916(23)$ \\
\hline
\end{tabular}

(b) ECMWF monthly occurrences (1996-2015)

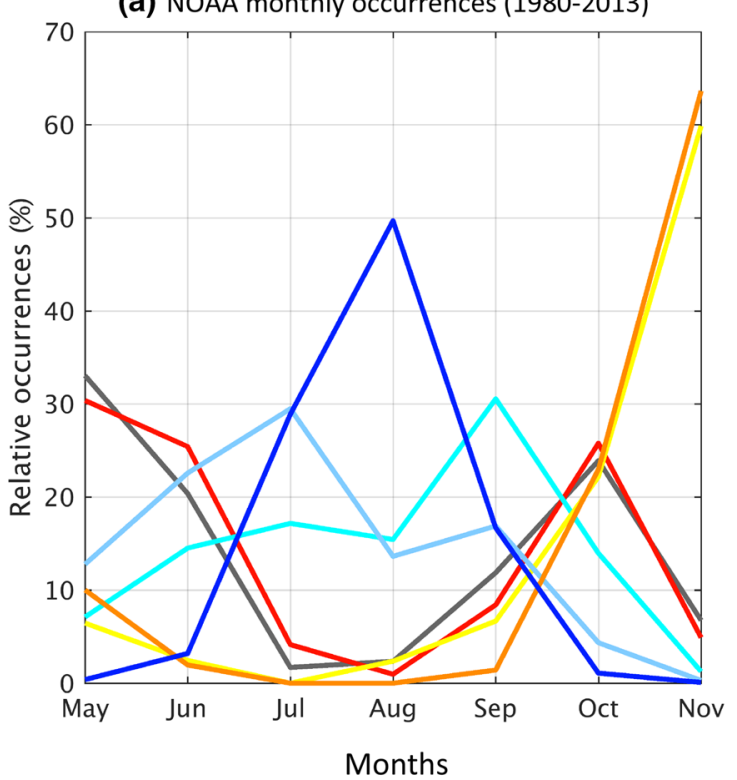

Fig. 4 Average counts of the occurrences of NOAA (1980-2103, a) and ECMWF week-1 (1996-2015, b) OLR regimes by calendar month

related to systematic biases (Table 2) and potential differences in the dynamics associated with each regime.

\subsection{Associated rainfall and circulation anomalies}

Rainfall anomaly composites based on CHIRPS/TRMM estimates, plotted in Figs. 5 and $6 \mathrm{a}-\mathrm{g}$ for the days assigned to each NOAA regime, exhibit a near one-to-one local correspondence between the polarity of the convection anomalies and those of precipitation for all seven regimes. The regime rainfall patterns are well reproduced in ECMWF week-1 (Fig. 6h-n) as indicated by differences of the same sign of the anomalies (Fig. 5h-n) that suggest differences in magnitude but not in structure. Despite some differences for the early WAM regimes (1 and 2), similarities reflect forecast fidelity in the 7-day range.

\subsubsection{Early WAM season (May-Jun)}

Regimes 1 and 2 prevail in May-Jun. Regime 1 is characterized by southwest-northeast orientated negative surface geopotential anomalies centered at about $10^{\circ} \mathrm{W}$ and $25^{\circ} \mathrm{N}$ along the west coast, and anomalies of opposite sign to the southeast (Fig. 7a). The low pressure cell is associated with a cyclonic circulation anomaly favoring moist air advection from the tropical Atlantic inland feeding increased convection (Fig. 2a), as shown by anomalous uplift in the wake of the cyclonic cell. The latter is located more to the south in ECMWF week-1 reforecasts leading to broader westerly anomalies over the tropical Atlantic (Fig. 8a), thus advecting moist air towards Guinean regions and leading to maximum wetting locally (Fig. 6h). For regime 2, ridging anomalies along the west coast at surface are associated with lowlevel easterly wind anomalies south of $10^{\circ} \mathrm{N}$ that weaken the westerly monsoon flow, inhibiting uplift (Fig. 7b) and 
(a) CHIRPS CLASS1

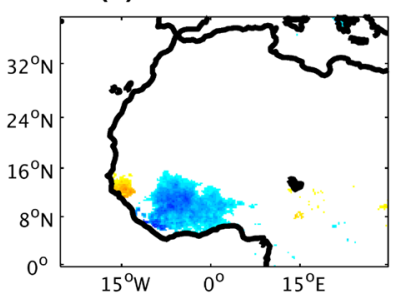

(c) CHIRPS CLASS3

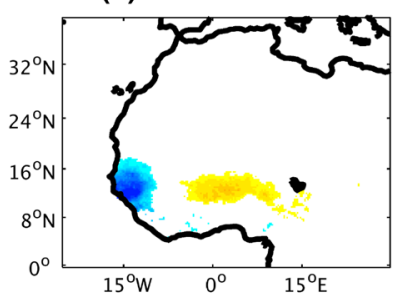

(e) CHIRPS CLASS5

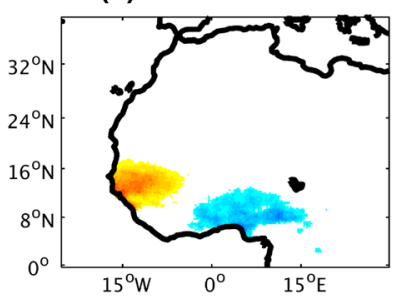

(g) CHIRPS CLASS7

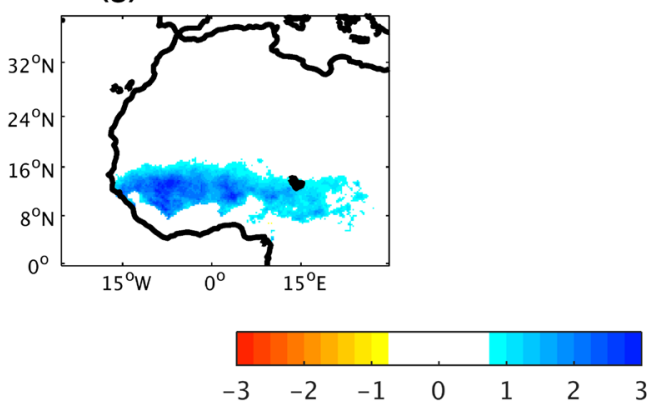

Fig. 5 Mean CHIRPS rainfall anomalies (a-g, in $\mathrm{mm} /$ day) for NOAA OLR regimes and differences with those from ECMWF week-1 reforecasts $(\mathbf{h}-\mathbf{n}$, blue/red contours correspond to positive/negative anomalies starting at and every $\pm 1 \mathrm{~mm} /$ day) for ECMWF OLR

convection broadly across the Sahel (Fig. 2b). Increased uplift over the East African Rift and anomalous low pressures over Asia with associated westerly anomalies in the Indian Ocean suggest modulations of the Walker circulation with stronger ascending and subsiding branches over East and West Africa, respectively, and weaker subsidence over Asia. Increased surface convergence there favors the circulation associated with the Somali jet and the Indian monsoon leading to wet conditions in Asian monsoon regions (Fig. 6b). These teleconnections are well reproduced in ECMWF (Figs. 7i and 8b) with large-scale ridging anomalies across Africa consistent with broader drying in the reforecasts compared to reanalyses (Fig. 5b). (h) ECMWF-CHIRPS CLASS1

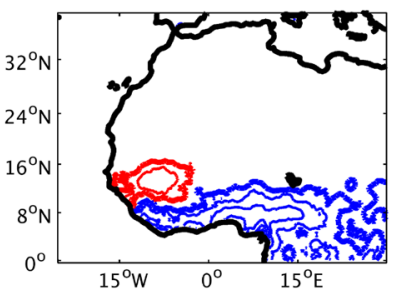

(j) ECMWF-CHIRPS CLASS3

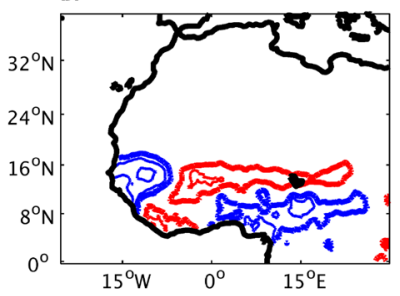

(I) ECMWF-CHIRPS CLASS5

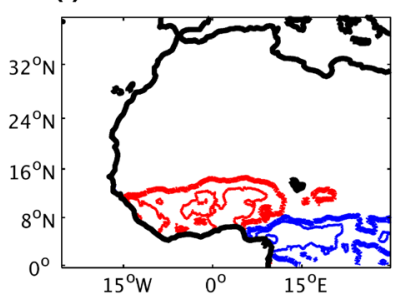

(n) ECMWF-CHIRPS CLASS7

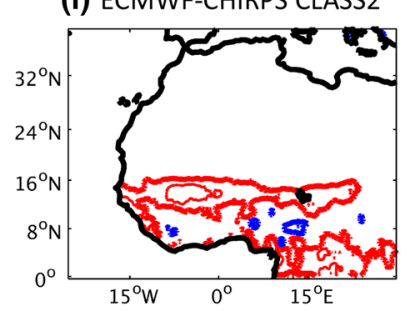

(k) ECMWF-CHIRPS CLASS4

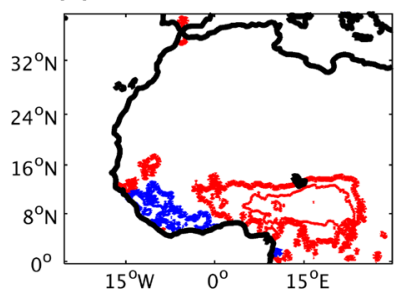

(m) ECMWF-CHIRPS CLASS6

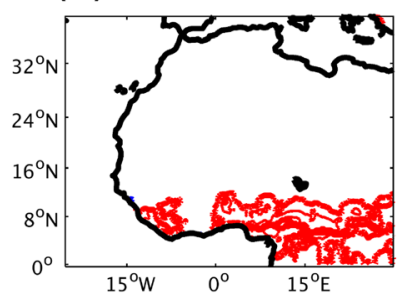

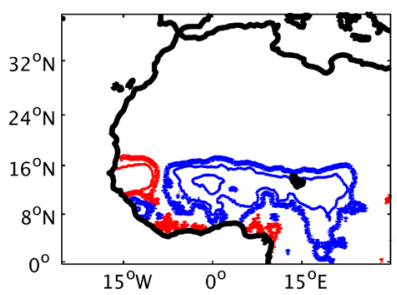

regimes (Fig. 6h-n) for the May-Nov season over their respective 1981-2013 and 1996-2015 periods. All anomalies and differences are significant at $5 \%$ level of Student's t-test

\subsubsection{Core WAM season (Jul-Sep)}

Regimes 3 and 5, associated with the propagation of anomalous convective cells along $15^{\circ} \mathrm{N}$, dominate the core WAM alongside ubiquitously wet regime 7 . Regime 3 is characterized by anomalous ridging inland along the west coast with maximum positive geopotential anomalies between 24 and $30^{\circ} \mathrm{N}$ (Fig. $7 \mathrm{c}$ ) and easterly anomalies south of $10^{\circ} \mathrm{N}$ concomitant with enhanced uplift at the coast and subsiding anomalies east of the prime meridian. Together with the cyclonic anomaly ahead of the ridge deflecting most warm moist air off the continent, wet conditions are favored over Senegal and drying over the Sahel interior (Fig. 5c). Ridging 

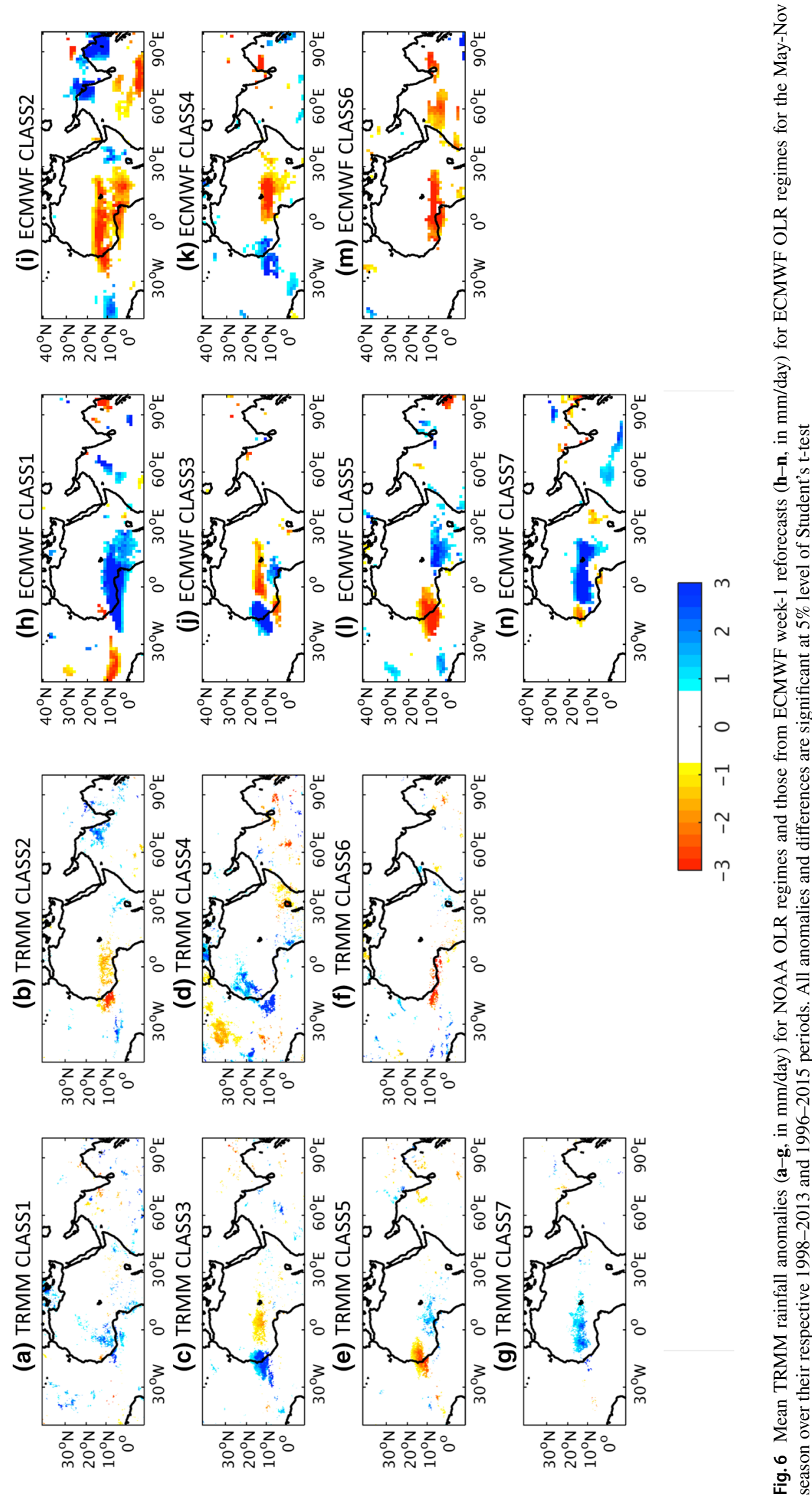
Fig. 7 Mean NCEP2 $850 \mathrm{hPa}$ geopotential heights (shadings in $\mathrm{m}$ ) and winds (vectors, in $\mathrm{m} / \mathrm{s}$ ) anomalies together with $500 \mathrm{hPa}$ vertical velocity anomalies (contours starting at $\pm 0.05 \mathrm{mb} / \mathrm{s}$ and every \pm 0.1 $\mathrm{mb} / \mathrm{s}$ ) for NOAA OLR regimes in the May-Nov season over the 1980-2013 period. All anomalies are significant at $5 \%$ level of Student's t-test (a) CLASS1

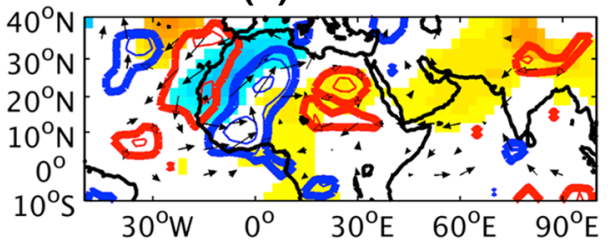

(c) CLASS3

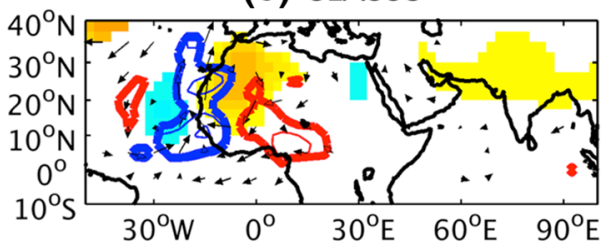

(e) CLASS5

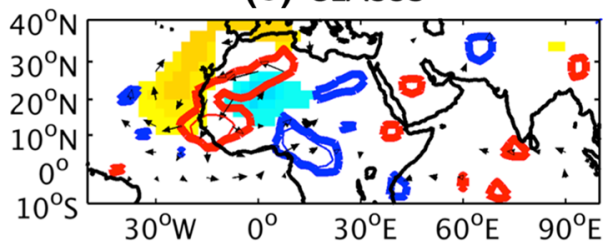

(g) CLASS7

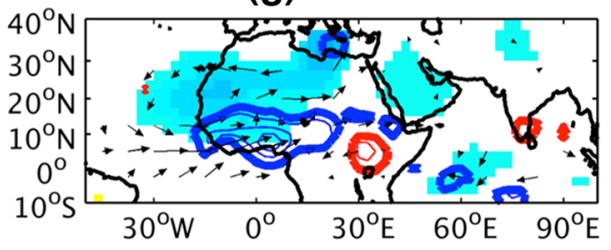

(b) CLASS2

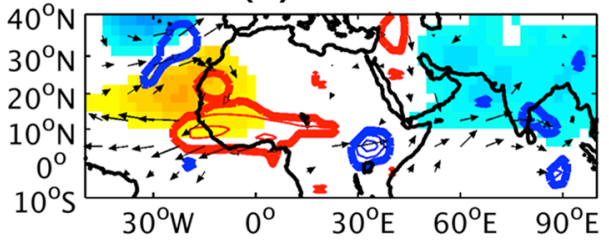

(d) CLASS4

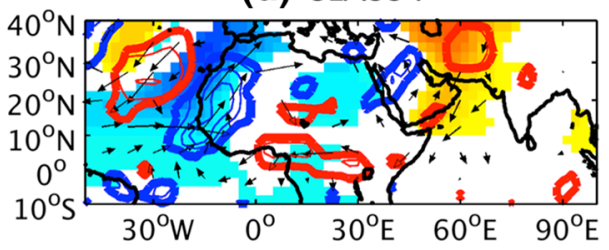

(f) CLASS6

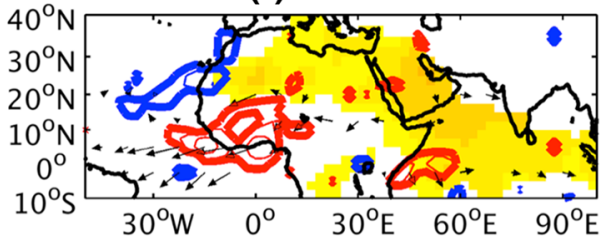

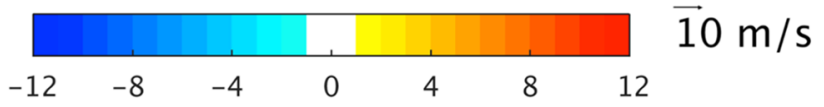

anomalies over Asia suggest modulations of the Walker circulation with stronger subsidence over the Sahel and a meridional shift of convection between the western and central Pacific. However, rainfall anomalies are not significant over Asia in both observations and model (Fig. 6c, j). ECMWF does not exhibit significant anomaly across Africa for regime 3 (Fig. 8c) suggesting less coherence in the propagation of the anomalous convective cell in ECMWF. This can be due to the sampling of day 1-7 instead of consecutive day 1 from the reforecasts, potentially degrading the signal associated with propagating tropical convection, but could also reflect internal variability in the model as noticed for this regime when computed from a single ensemble member instead of the ensemble mean (not shown). The anticyclonic anomaly transits westwards from regime 3 to 5 leading to negative geopotential anomalies to the east and maximum inland at $18^{\circ} \mathrm{N}$ and between $12^{\circ} \mathrm{W}-12^{\circ} \mathrm{E}$, which are associated with an anomalous cyclonic circulation resulting in easterly anomalies to the south (Fig. 7e). Anomalous uplift in the wake of the trough and subsidence ahead agree with rainfall anomalies in Fig. 5e. The anticyclonic anomaly is well reproduced in ECMWF despite the cyclonic cell behind not being as marked (Fig. 8e) similarly to regime 3, potentially reflecting week-1 sampling and internal variability in the model. Moreover, regime 5 is found to be more frequent in October in ECMWF (Fig. 4b), when prevailing subtropical anomalies are consistent with increased control from the midlatitudes in the late season. By regime 7, the anomalous trough prevails across West Africa with westerly anomalies south of $20^{\circ} \mathrm{N}$ and anomalous uplift leading to broad wetting (Fig. 5g). Upper level geopotential anomalies of lower amplitude for core WAM regimes (not shown) compared to others suggest deeply tropical patterns. The trough and associated westerly anomalies are well reproduced in ECMWF (Fig. 8e) which also exhibits linkages with Indian monsoon regions, where anticylonic and easterly anomalies suggest modulations of local convection opposite to those in regime 2 .

\subsubsection{Late WAM season (Oct-Nov)}

Regimes 4 and 6, characterized by anomalous cells propagating across the Sahel along $24^{\circ} \mathrm{N}$, are prevalent during the end of the WAM season. For regime 4, maximum negative 
Fig. 8 Mean ECMWF week-1 $850 \mathrm{hPa}$ geopotential heights (shadings in $\mathrm{m}$ ) and winds (vectors, in $\mathrm{m} / \mathrm{s}$ ) anomalies for ECMWF week-1 OLR regimes in the May-Nov season over the 1996-2015 period. All anomalies are significant at 5\% level of Student's t-test (a) CLASS1

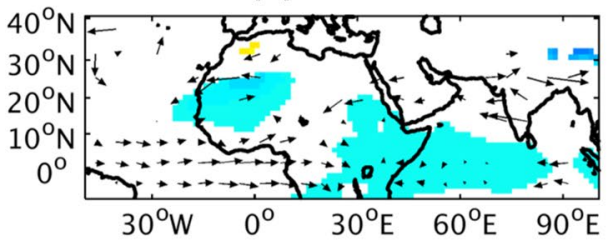

(c) CLASS3

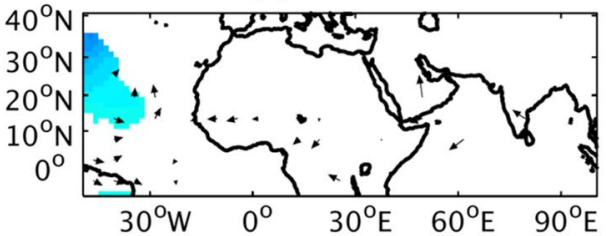

(e) CLASS5

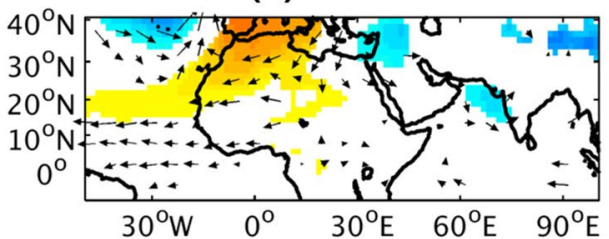

(g) CLASS7 (b) CLASS2

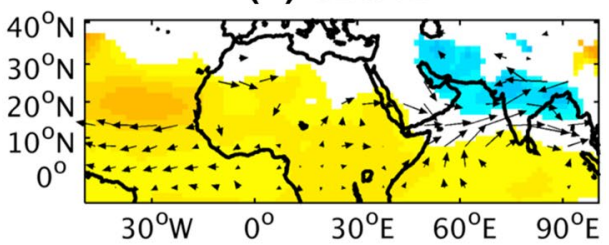

(d) CLASS4

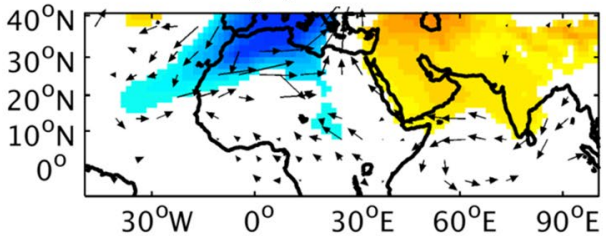

(f) CLASS6

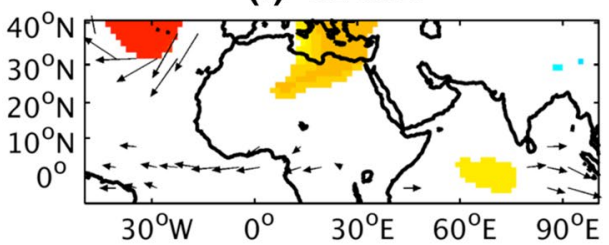

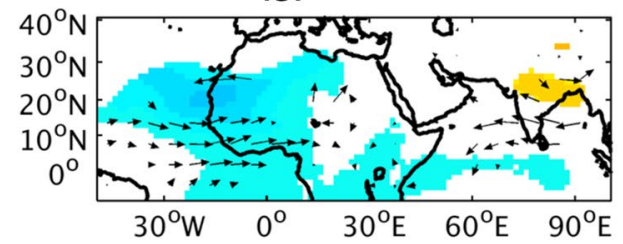

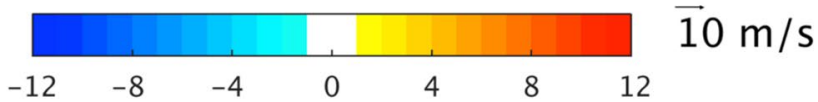

geopotential anomalies off the west coast north of $18^{\circ} \mathrm{N}$ are accompanied by an anomalous cyclonic circulation (Fig. 7d) sustaining moisture advection from the tropical Atlantic inland. Significant uplift anomalies in the wake of the trough are maximum over Senegal extending northwards with increased rainfall locally (Fig. 5d). The anomalous cyclonic cell is located further to the northwest for regime 4 in ECMWF (Fig. 8d) compared to reanalyses, which could explain rainfall differences in Fig. 5k. However, contrasting ridging anomalies over west Asia are consistent with the large-scale anomalies in the reanalyses. Ridging anomalies maximum north of $18^{\circ} \mathrm{N}$ for regime 6 and easterly anomalies southwards weaken the westerly monsoon flow towards the Guinea Gulf, where subsidence (Fig. 7f) and dry conditions prevail (Fig. 5f). Anomalous ridging is limited to the subtropics in ECMWF (Fig. 8f) which might again be associated with week-1 sampling and internal variability as for regime 3 , but also suggests marked control from the midlatitudes in the late WAM.

Overall, the regime OLR and attendant circulation anomalies are consistent with dynamical modes of variability at subseasonal time-scales (Janicot et al. 2011). Early and core WAM regimes resemble the Sahel mode (at $t_{0}+2$ and $t_{0}+6 / 8$ for regimes 1 and 2 , and at $t_{0}-12, t_{0}-6$ and $t_{0}-2 / t_{0}$ for regimes 3,5 and 7). The core WAM regime 7 also bears similarities to the African MJO mode at $t_{0}$. Late WAM regimes resemble the QBZD mode (at $t_{0}+4$ and $t_{0}+6$ for regimes 4 and 6 ). This is emphasized by regime seasonalities (Fig. 4a) matching the respective prevalence of the Sahel, African MJO and QBZD modes in June-July, July-August and from September.

\subsection{Frequencies of occurrence and MJO phases}

Given that the MJO is known to be a primary source of predictability at subseasonal time-scales, the frequency of occurrence of each regime is broken by MJO phases in Fig. 9. Panels a-g represent the distribution of days belonging to each OLR regime across the $8 \mathrm{MJO}$ phases, while panel $h$ displays the percentages of regime occurrences by MJO phase at lead 0. In Fig. 9a-g, the fraction of days in each regime relative to $\mathrm{MJO}$ phase, i.e., the number of days that the MJO phase precedes a given daily regime, is relative 
(a) CLASS1

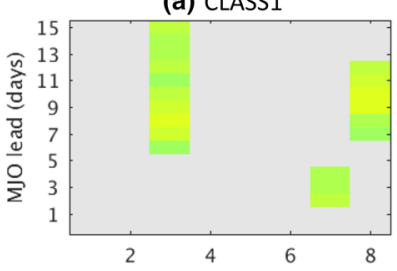

(c) CLASS3

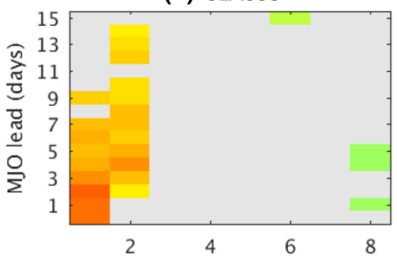

(e) CLASS5

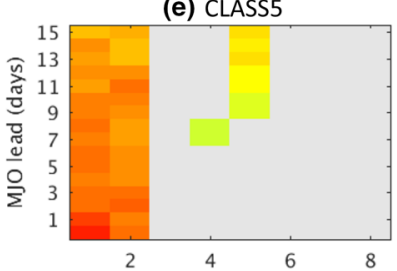

(g) CLASS7
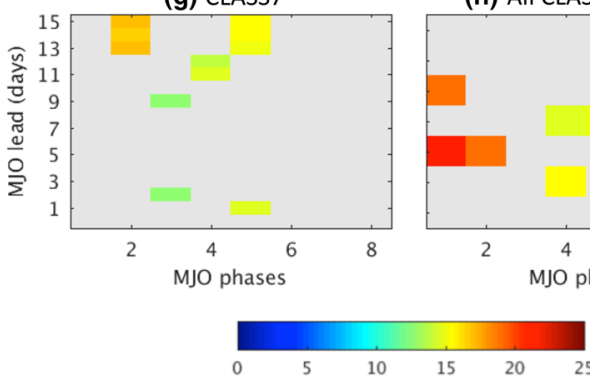

Fig. 9 Distribution of the fraction of days belonging to each regime, relative to the total number of days spent in each, according to MJO phase, numbered from 1 to 8 on the $\mathrm{x}$-axis. The ordinate in panels a$\mathbf{g}$ indicates the lead time, in days between 0 and 15, that MJO phase precedes the occurrence of the daily OLR regime; $\mathbf{h}$ depicts the contingency matrix at lead 0 , and shows the proportion of regime occurrences by MJO phase. Counts not significant at 5\% level based on Monte Carlo simulations are shaded in grey

to the total number of days spent in that regime. Figure $9 \mathrm{~h}$ displays the percentages of regime occurrences by MJO phase as observed on the days of occurrence of each regime (i.e., this is the contingency matrix at 0 lead). Regime 1 exhibits the least modulation according to MJO phases at all leads (Fig. 9a). The early WAM regime 2 is more frequent during MJO phase 6 at no lead (Fig. 9h) when convection is enhanced over the western Pacific, and favored when MJO phase 3 leads about 10 days (Fig. 9a, b) and convection is enhanced over the Indian Ocean, consistently with regime 2 teleconnections (Fig. 7b). During the core WAM, regimes 3 and 5 frequencies are maximum during MJO phases $1-2$ at all leads (Fig. 9c, e and h), consistent with increased convection over the western Indian Ocean-West Africa (Wheeler and Hendon 2004). The low variations of regimes 3 and
5 relationship to MJO phases 1-2 across lead time could be due to temporal sampling, since these are the only two regimes prevailing in both July and September when MJO sensitivity might be contrasted locally due to seasonality. Regimes 5 and 7 are favored when MJO phases 4-5 and 2 lead by a 1-2 weeks, i.e., when convection is enhanced over the Maritime Continent and the Indian Ocean, respectively. Late WAM regimes 4 and 6 are more frequent during MJO phases 4-7 at all leads (Fig. 9d, e and h) when convection is enhanced from the MC to the western Pacific, consistent with the equatorial wave mechanism propagating MJOinduced latent heat anomalies in the warm pool (Lavender and Matthews 2009). Overall, regime frequencies are significantly related to the MJO with lagged relationships suggesting potential for predictability, in particular during the early WAM for MJO phases 3 and 6, when convection is enhanced over the Indian Ocean and the western Pacific, respectively.

\subsection{Year-to-year variability and SST teleconnections}

Figure 10a-g displays NOAA and ECMWF week-1 yearly frequency anomalies computed as the differences between the yearly number of occurrences of each regime in May-Nov and mean values computed from the respective 1980-2013 and 1996-2015 climatologies. These are $22 / 23,39 / 31,33 / 28,13 / 19,41 / 23,27 / 26$ and $38 / 46$ days for NOAA/ECMWF regimes 1 to 7, consistent with Tables 1, 2. ECMWF regime frequencies are comparable to those from NOAA. However, departures in observed and forecasted frequencies for regimes 3 and 5 might be attributed to both the model systematic biases and the different periods analyzed. To examine how variations in the frequency of occurrence of each NOAA regime are related to seasonal rainfall, the five wettest/driest years computed from CHIRPS estimates over West Africa between $\left[5-20^{\circ} \mathrm{N} ; 20^{\circ} \mathrm{W}-30^{\circ} \mathrm{E}\right]$ are shown in Figure 10h. Regimes 2, 3 and 6 are less frequent during most wet years. Opposite relationships with regimes 2 and 6 are true for dry years, when regime 5 is less frequent. Regime 7 is more frequent during wet years and is concomitant with the observed wetting since the 1990s (Fig. 10h).

Regime frequencies are mainly related to the tropical Indian Ocean and North Atlantic in the early WAM (Fig. 11a, b), to El Niño in the core season (Fig. 11c) and to the tropical Atlantic and Pacific extra-tropics in the late WAM (Fig. 11d, f). During the early WAM, regime 2 teleconnections with the tropical Indian Ocean (Fig. 11b) mirror relationships to the atmospheric circulation over Indian monsoon regions (Fig. 7b), where subsequent modulations of cloud cover and thus radiation forcing act to cool local SSTs. In the core WAM, increased regime 3 frequencies with El Niño (Fig. 11c) are consistent with drying in the Sahel for warm ENSO phases (Janicot et al. 1996, 2001; Lebel et al. 2003; Joly and Voldoire 2009), through modulations of the 
Fig. 10 Time-series of the differences in number of days spent in each OLR regime $(\mathbf{a}-\mathbf{g})$ during each May-Nov season compared to the long-term mean for NOAA and ECMWF week-1 reforecasts over the 1980-2013 and 1996-2015 periods, respectively. Black crosses/grey stars indicate the five wettest/driest years from the CHIRPS rainfall index (land only) averaged over a domain between $\left[5-20^{\circ} \mathrm{N} ; 20^{\circ} \mathrm{W}-30^{\circ} \mathrm{E}\right]$ (h) (a) CLASS1 per year

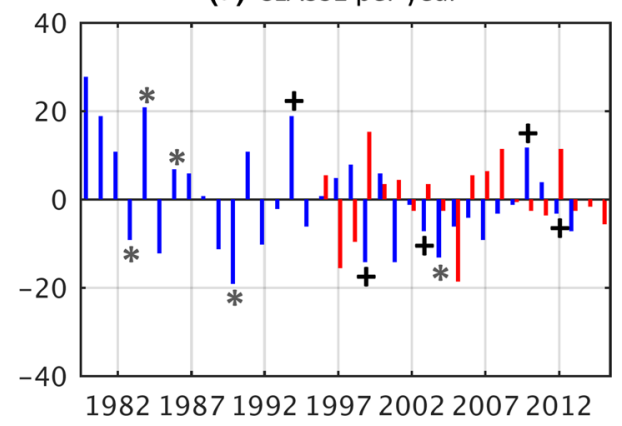

(c) CLASS3 per year

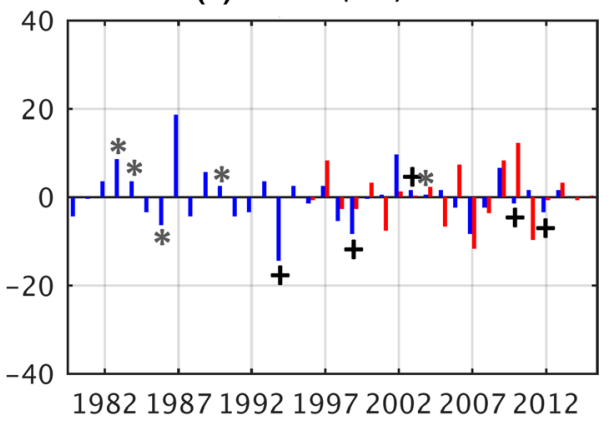

(e) CLASS5 per year

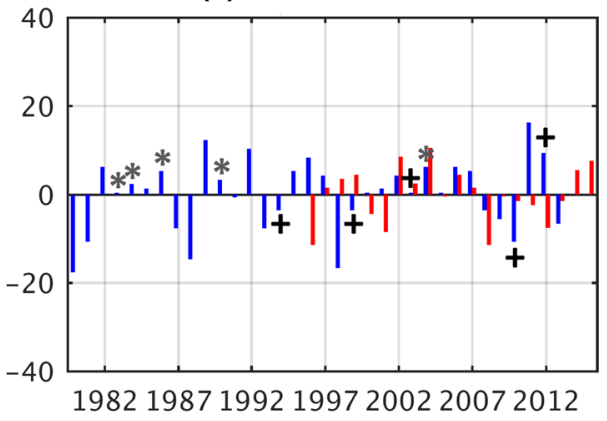

(g) CLASS7 per year

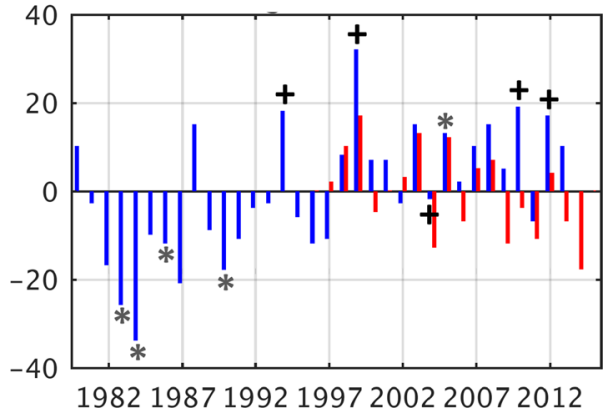

(b) CLASS2 per year

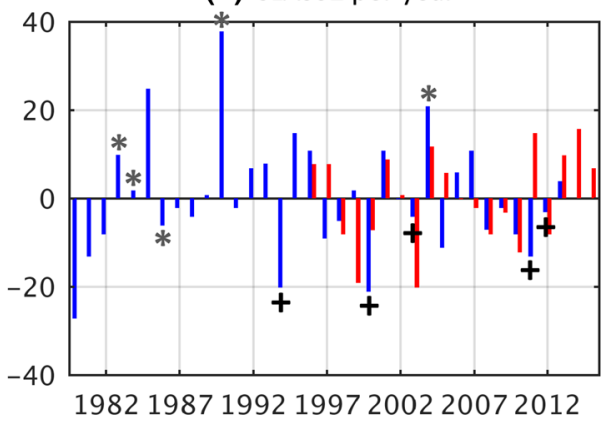

(d) CLASS4 per year

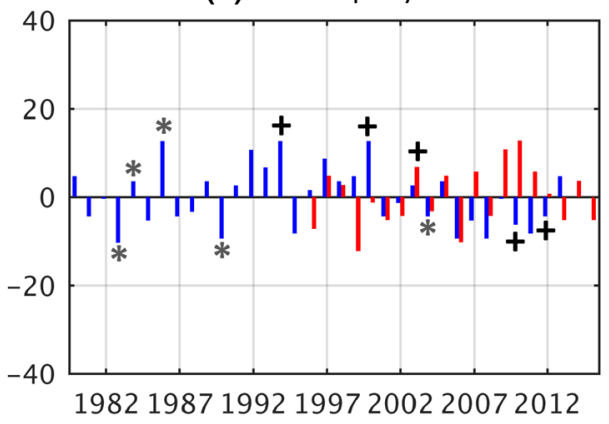

(f) CLASS6 per year

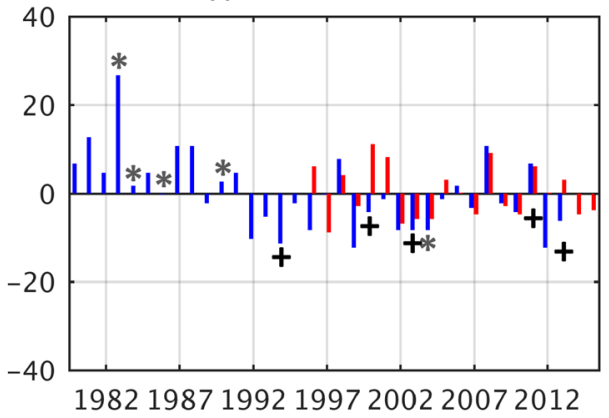

(h) West African rainfall index

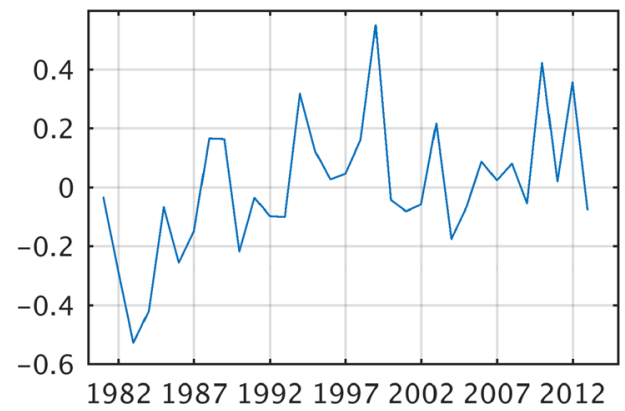

Walker circulation with westerly anomalies over the tropical Atlantic and increased subsidence over the Sahel (Fig. 7c). The limited significance of dry anomalies related to teleconnections over Asia (Fig. 6c, j) could reflect the non-linearity of recent ENSO impacts (Gadgil et al. 2005; Krishna Kumar et al. 2006). Regime 7 correlations to global SSTs agree with the contribution of global warming to Sahel wetting since the 1990s (Giannini 2015).
Yearly rainfall anomalies are next reconstructed from the yearly regime frequencies (Figure 10), that are multiplied by the rainfall anomalies associated to each regime, and then averaged spatially over the WAM domain between [5-20 $\left.\mathrm{N} ; 20^{\circ} \mathrm{W}-30^{\circ} \mathrm{E}\right]$ for both NOAA (using CHIRPS for corresponding rainfall) and ECMWF week-1, as shown in Fig. 12 alongside their respective spatially averaged rainfall anomalies. Spatially averaged rainfall anomalies from the model 
Fig. 11 Heterogeneous correlations (shadings) between yearly NOAA OLR regime occurrences (i.e., time-series in Fig. 10a-g) and May-Nov OISST over the 1982-2013 period. All correlations are significant at 5\% level using Monte Carlo simulations (a) CLASS1 SST

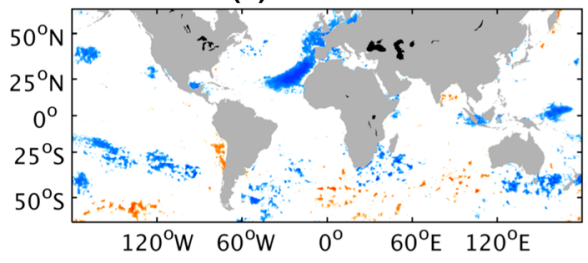

(c) CLASS3 SST

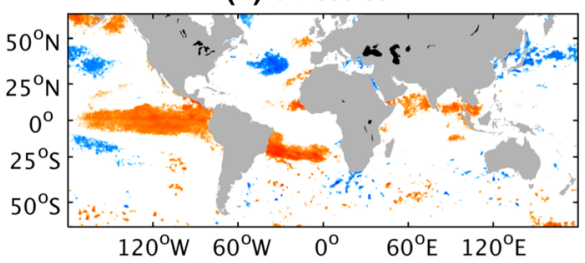

(e) CLASS5 SST

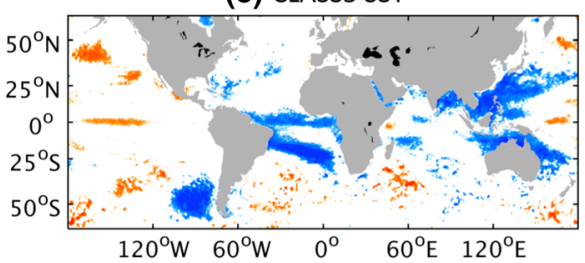

(g) CLASS7 SST

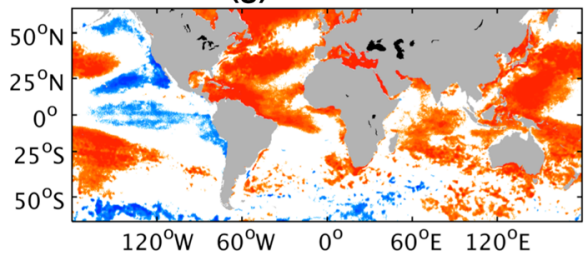

(b) CLASS2 SST

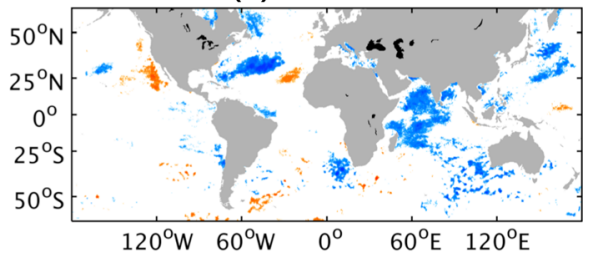

(d) CLASS4 SST

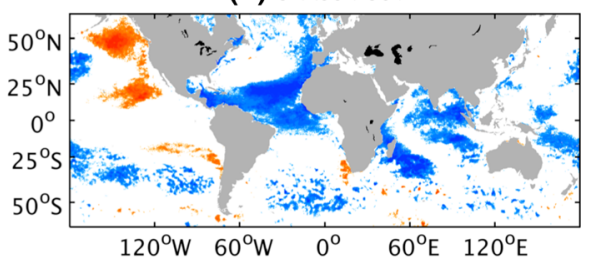

(f) CLASS6 SST

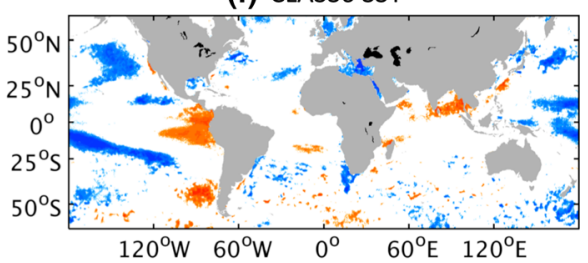

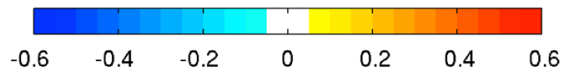

are highly correlated with those from observations $\left(R_{A V G}=\right.$ $0.75)$, as well as rainfall anomalies reconstructed from their respective regime frequencies and rainfall anomalies $\left(R_{R E C}\right.$ $=0.58$ ), which reflects substantial coherence between yearly regime proportion and their impact on rainfall between model and observations. Reconstructed anomalies are also significantly correlated to those spatially averaged for both NOAA and ECMWF $\left(R_{N O A A}=0.70\right.$ and $\left.R_{E C M W F}=0.77\right)$ over their respective 1981-2013 and 1996-2015 periods, indicating that WAM rainfall interannual variability is well represented by regime frequencies.

\section{Predictability from submonthly reforecasts}

ECMWF ensemble mean reforecasts at week-1 to -4 leads are here used to examine the predictability of convection regimes. Euclidean distances are used to measure similarities between daily OLR patterns from ECMWF reforecasts issued in May-Nov for the 1996-2013 period and each regime computed from 1980 to 2013 NOAA daily OLR (see Sect. 2.2), in order to classify each daily ECMWF reforecast as a single regime occurrence for which Euclidean distance is minimized. ECMWF ensemble mean reforecasts are chosen to take advantage of the 11-member ensemble and thus representing the best estimate of the model signal.

\subsection{Reproducibility versus lead time}

The sequence of regimes observed in NOAA and forecasted by ECMWF at week-1 to -4 leads (i.e., over the periods from $[d+1, d+7]$ to $[d+22, d+28]$ for a forecast issued on day $d$ ) are plotted in Fig. 13 for Thursday starts in the 1996-2013 May-Nov seasons. At week-1 lead, the sequence of regimes forecasted by ECMWF bears some similarities to the one observed in NOAA at the begining of the season but also displays substantial differences reflecting ECMWF systematic biases (Table 2). Regime 2 occurrences are not captured by ECMWF in the late WAM but those at the beginning of 


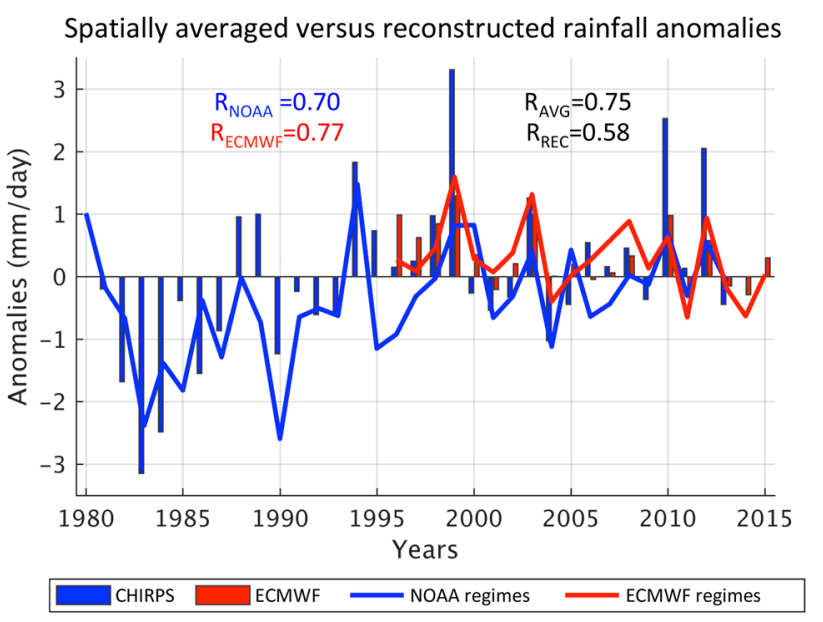

Fig. 12 Yearly CHIRPS (blue bars) and ECMWF week-1 (red bars) rainfall averaged over $\left[5-20^{\circ} \mathrm{N} ; 20^{\circ} \mathrm{W}-30^{\circ} \mathrm{E}\right]$ and reconstructed from the regime frequencies and averaged rainfall anomalies (lines) over 1981-2013 and 1996-2015, respectively. Spatially averaged rainfall anomalies from CHIRPS and ECMWF are correlated at $R_{A V G}=0.75$ and those reconstructed from ECMWF and NOAA WRs at $R_{R E C}=$ 0.58 . Spatially averaged and reconstructed anomalies are correlated at $R_{N O A A}=0.70$ and $R_{E C M W F}=0.77$ for NOAA and ECMWF, respectively, all correlations being significant at $1 \%$ level using Monte Carlo simulations

the season are well reproduced up to week-4 leads, suggesting potential predictability of late onset due to dry spells in the early rainy season. Interestingly, the relative frequencies of regimes 1 and 7 switching from a more frequent regime 1 before mid-June to highest frequencies of regime 7 after, might also reflect the onset of the monsoon over the Sahel. As lead increases, skill decreases with more differences compared to observation.

Performance diagrams are used for visually representing forecast quality (Roebber 2009). They are commonly used in the context of numerical weather predictions and are here applied to evaluate the skill of ECMWF forecasts in predicting daily regime occurrences. Figure 14 summarizes the success ratio (SR), the probability of detection (POD), bias, and critical success index (CSI). Dashed lines represent bias scores with labels on the outward extension of the line, while labeled solid contours are CSI. For good forecasts, POD, SR, bias, and CSI are close to 1 and a perfect forecast will thus lie in the upper right of the diagram, while deviations in a particular direction indicate relative differences in POD and SR, and thus bias and CSI (Roebber 2009). All forecasts exhibit relatively low skill with most points in Fig. 14 clustered left of the bias $=1.0$ line. Those of regime 2 , located to the right, are the exception. They have the highest success ratio but also the lowest detection rate at all leads, reflecting ECMWF systematic bias (Table 2) magnified with lead time (Fig. 13). The prevalence of regime 2 in June for ECMWF reforecasts (Fig. 4b) corroborates the potential for skillful

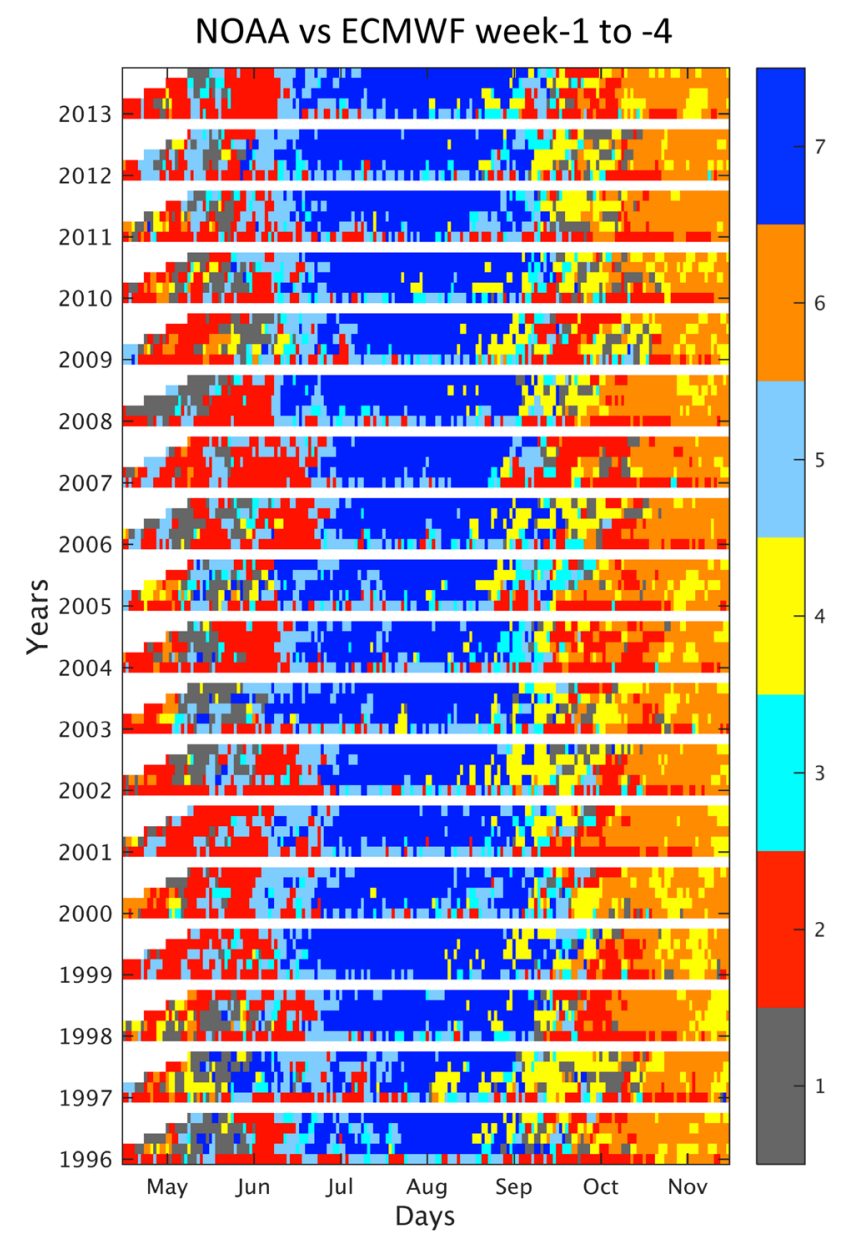

Fig. 13 Day-to-day classifiability per May-Nov seasons during the 1996-2013 period when each day is projected onto NOAA OLR 7-cluster partition obtained over the 1980-2013 period. For each year, the first line is the composite weekly sequence observed in NOAA for every ECMWF Thursday starts, while the lines above correspond to those forecasted by ECMWF at week- 1 to -4 leads (i.e., periods from $[d+1, d+7]$ to $[d+22, d+28]$ for a forecast issued on day $d)$

predictions during the WAM pre-onset period (Fontaine and Louvet 2006). Results from the regime analysis in section 3 suggest that predictability might be drawn primarily from the MJO, to which regime 2 frequency of occurrences exhibits maximum relationship in phase 3 more than 10 days in advance (Fig. 9b), but also from regime 2 teleconnections with the Indian monsoon sector (Figs. 5b, 6b/j and 7b).

\subsection{Application to WAM onset predictions}

Dry spells in the early WAM can have dramatic impacts on crop yield (Janicot et al. 2011) by increasing the likelihood of a false start, which represents the largest agronomical risk for local stakeholders in West Africa (Fitzpatrick et al. 2015). Based on the above results, we next focus on assessing the predictability of onset date using the forecasted 
Fig. 14 Performance diagram (Roebber 2009) for each regime (colors) at week-1 (diamonds), week-2 (circles), week-3 (squares) and week-4 (triangles) leads during the May-Nov season from 1996 to 2013

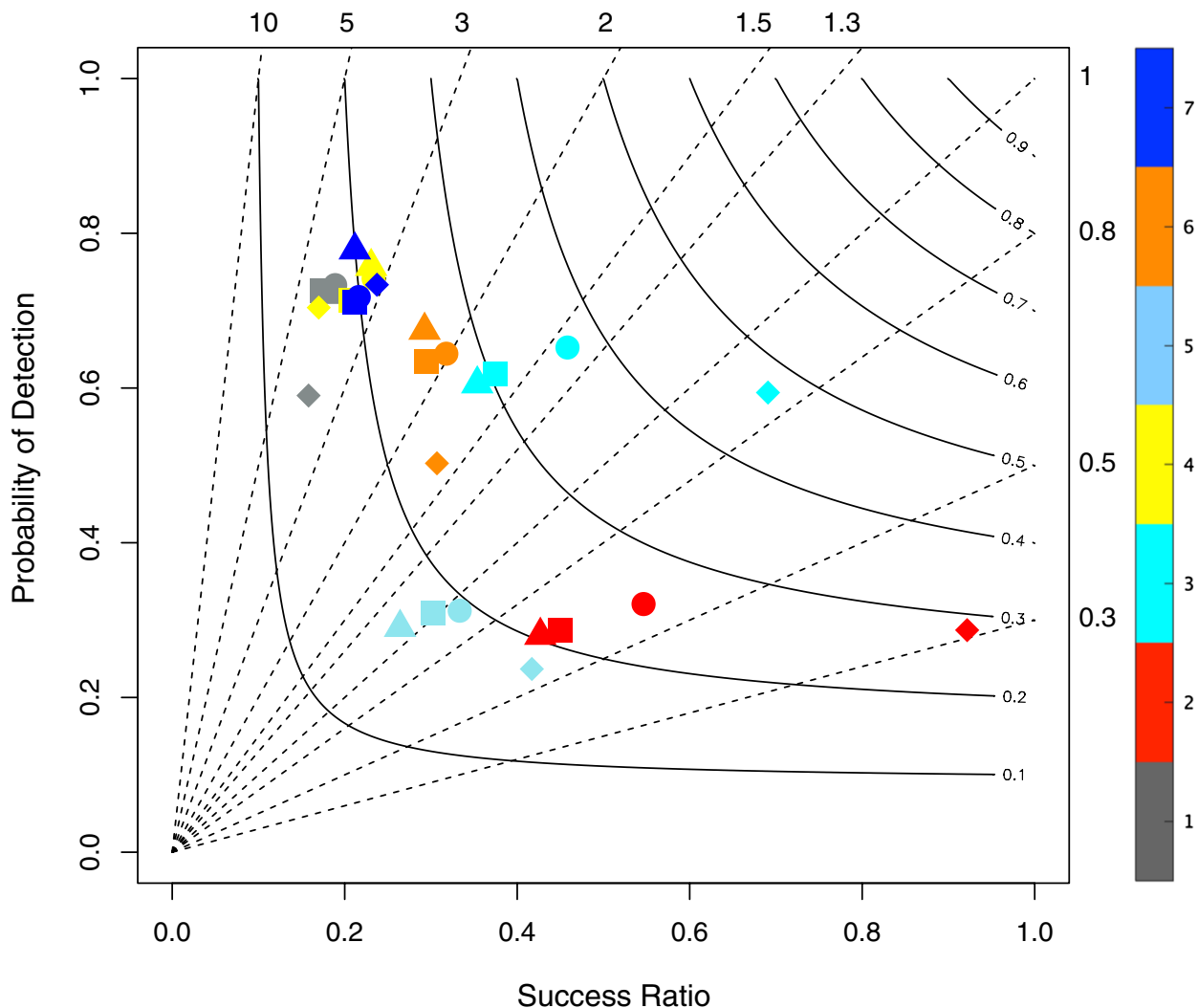

counts of dry regime 2 during the mid-May to mid-July period as a predictor, such that increased occurrences of regime 2 in the early season would translate in delayed WAM onset. Onset dates measured by the WAMOI (see Sect. 2.1) are used as a benchmark following the definition of Fontaine and Louvet (2006) over the $\left[10^{\circ} \mathrm{E}-10^{\circ} \mathrm{W}\right]$ window, where a clear meridional land-sea contrast exists. WAMOI values increase when the rainbelt migrates northwards but decrease with the southward migration of rains. Mean onset dates around June 22-23 for TRMM and GPCP (Table 3) and June 24-25 for CHIRPS (computed over 1981-2013 since the period after 1996 leads to June 30-July 1) correspond well with the Jun 24-25 onset date computed from 19962013 ECMWF week-1 ensemble mean. These estimates are earlier than those from Fontaine and Louvet (2006) over 1979-2004 (June 28-29) with a little more spread (from 10 to 13 days) than the 8-day standard deviation noted in Janicot et al. (2011), potentially reflecting differences across datasets and/or temporal sampling, including the wettening observed since the 1990s.

Monsoon onset indices from CHIRPS, TRMM, GPCP and ECMWF week-1 rainfall estimates are next computed over the 1996-2015 period together with yearly regime 2 counts from mid-May to mid-June based on daily OLR from NOAA and ECMWF reforecasts from week-1 to -4 leads. Maximum correlations between TRMM and GPCP WAMOI (0.85) suggest better agreement between both indices than with CHIRPS (0.57 and 0.29, respectively). Similarly, ECMWF week-1 WAMOI exhibits greater correlations with TRMM $(0.79)$ and GPCP $(0.70)$ than CHIRPS (0.50). Regime 2 counts and WAMOI are significantly correlated when both are computed from ECMWF week-1

Table 3 Characteristics of West African Monsoon Onset Indices (WAMOI) from CHIRPS, TRMM and GPCP dataset as well as ECMWF week-1 and their relationships to ECMWF week-1 to -4 regime 2 counts

\begin{tabular}{|c|c|c|c|c|}
\hline & $\begin{array}{l}\text { CHIRPS } \\
\text { WAMOI }\end{array}$ & $\begin{array}{l}\text { TRMM } \\
\text { WAMOI }\end{array}$ & $\begin{array}{l}\text { GPCP } \\
\text { WAMOI }\end{array}$ & $\begin{array}{l}\text { ECMWF } \\
\text { WAMOI }\end{array}$ \\
\hline Period & 1981-13 & 1998-13 & 1997-13 & 1996-13 \\
\hline Mean onset date & June $24-25$ & June $22-23$ & June $22-23$ & June $24-25$ \\
\hline $\begin{array}{l}\text { TRMM } \\
\text { WAMOI }\end{array}$ & $0.57 * * *$ & 1 & $0.85 * * *$ & $0.79 * * *$ \\
\hline GPCP WAMOI & 0.29 & $0.85 * * *$ & 1 & $0.70 * * *$ \\
\hline $\begin{array}{l}\text { ECMWF } \\
\text { WAMOI }\end{array}$ & $0.50^{*}$ & $0.79 * * *$ & $0.70 * * *$ & 1 \\
\hline Week-1 Class 2 & -0.05 & -0.04 & -0.07 & $0.44 *$ \\
\hline Week-2 Class 2 & -0.02 & 0.17 & 0.23 & $0.56 * * *$ \\
\hline Week-3 Class 2 & 0.09 & 0.40 & $0.45^{*}$ & $0.65 * * *$ \\
\hline Week-4 Class 2 & -0.02 & 0.10 & 0.28 & $0.60 * * *$ \\
\hline
\end{tabular}

Correlations significant at 10,5 and $1 \%$ level of significance using Monte Carlo simulations are respectively indicated with $*$, ** and $* * *$ 
reforecasts (0.44) confirming that more occurrences of regime 2 from mid-May to mid-June result in delayed WAM onset and thus, that regime 2 frequency is a good predictor for onset date in the model ensemble mean. Correlations between ECMWF forecasted regime 2 counts during the mid-May to mid-June period and WAMOI are enhanced as lead time increases $(0.56,0.65$ and 0.60 at week-2, -3 and -4 leads) similarly to ECMWF regime 2 count correlations with observed WAMOIs, which are maximized and significant at week-3 lead ( 0.45 for GPCP). This is reflected in Figure 15 by greater correlations compared to other leads between ECMWF regime 2 counts and onset dates, when defined locally at each grid point from TAMSAT merged rainfall estimates (see Sect. 2.1). Skillful onset date predictions based on regime 2 forecasted counts could be drawn from regime 2 relationships to MJO phase 3 beyond 10 days lead (Fig. 9b), when convection is enhanced over the Indian Ocean. Potential teleconnections through modulations of the Walker circulation (Fig. 7b) could translate into skill beyond two weeks in predicting dry spells over West Africa. This is an alternative to approaches using Guinea Gulf rainfall as the main predictor, whose predictive capability decreases quickly with lead, as noted by Fontaine and Louvet (2006) who recommended new schemes based on historical data and numerical simulations. The weather typing discussed here provides that opportunity.

\section{Conclusions}

This study aimed to identify recurrent convection regimes during the broader WAM season (May-Nov), using a dynamical clustering ( $k$-means) of 2.5-degree gridded daily NOAA OLR observations (1981-2013), and to assess their reproducibility in ECMWF submonthly reforecasts (1996-2015) before presenting an application to WAM onset date prediction, whose potential skill is evaluated from ECMWF ensemble mean reforecasts at week-1 to week-4 leads. Seven patterns of anomalous convection (Fig. 2) are identified, each related to distinct rainfall anomalies over West Africa which are well reproduced by 1996-2015 ECMWF week-1 reforecasts (Figs. 3, 4, 5, 6 and 8) despite systematic biases that might be associated with both week-1 sampling (i.e., day 1-7 and not consecutive day 1 of the reforecasts) and internal variability in the model. Two regimes prevailing during the early WAM season (May-Jun) and in October (Fig. 4a) are related to cyclonic (regime 1) and anticyclonic (regime 2) anomalies respectively (Fig. 7a, b). Increased moisture advection from the tropical Atlantic and uplift inland for regime 1 result in wet conditions in the central Sahel/Guinea Gulf and drying over the western Sahel/Senegal (Fig. 5a). A weakened monsoon flow and subsiding anomalies result in drying across the Sahel for regime 2 with modulations of the Walker circulation suggesting teleconnections with the Indian monsoon (Figs. 5b, 6b/i).

Other regimes are related to westward propagating anomalous convective cells along two distinct wave trains at $15^{\circ} \mathrm{N}$ and $24^{\circ} \mathrm{N}$ during the core (Jul-Sep) and late (Oct-Nov) WAM, respectively, resembling 3-5 and 6-9 days AEWs
Fig. 15 Heterogeneous correlations between regime 2 counts in ECMWF week-1 to week-4 and onset dates computed over the 1996-2015 period at each grid point from TAMSAT merged rainfall estimates
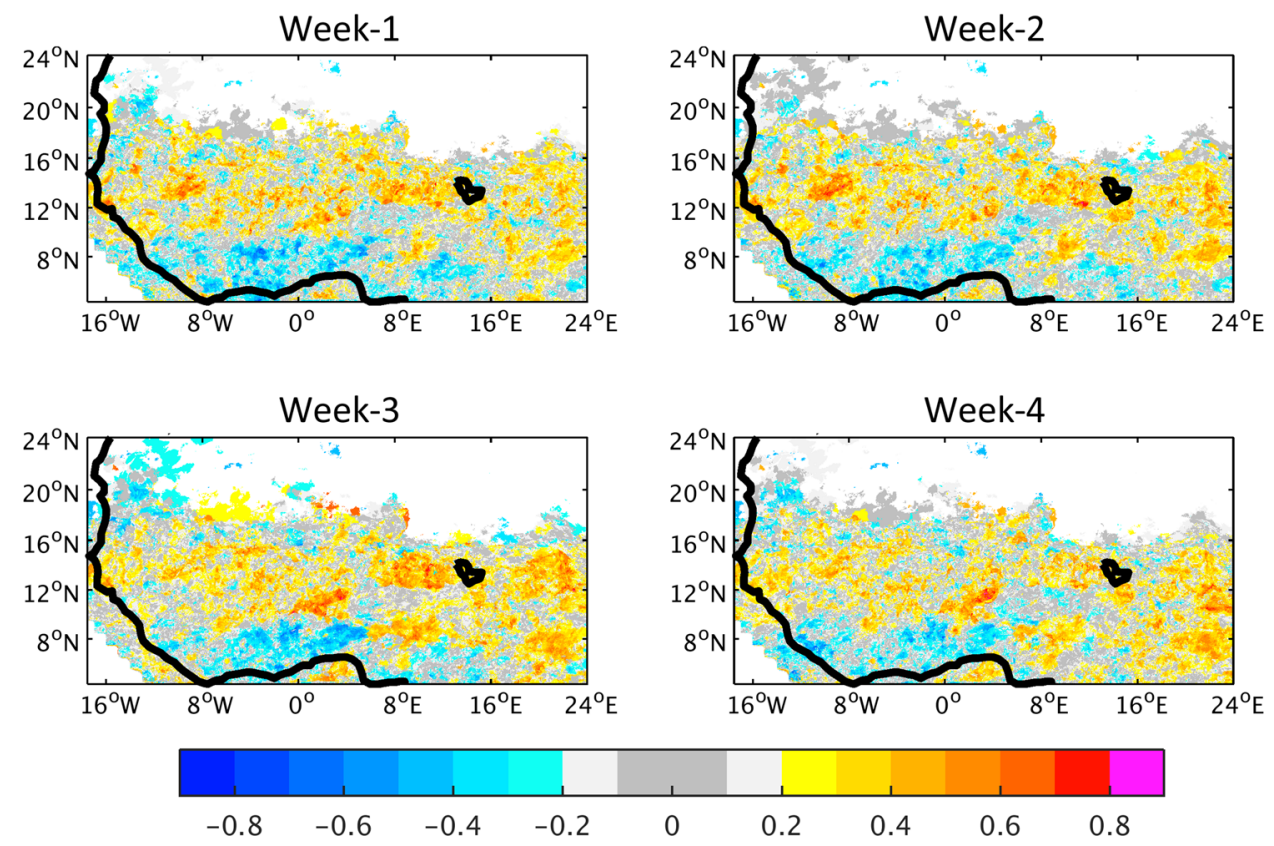
Fig. 16 Schematic showing modulations of the Walker circulation for West African dry spells related to regime 2 and their teleconnection to the Indian monsoon sector

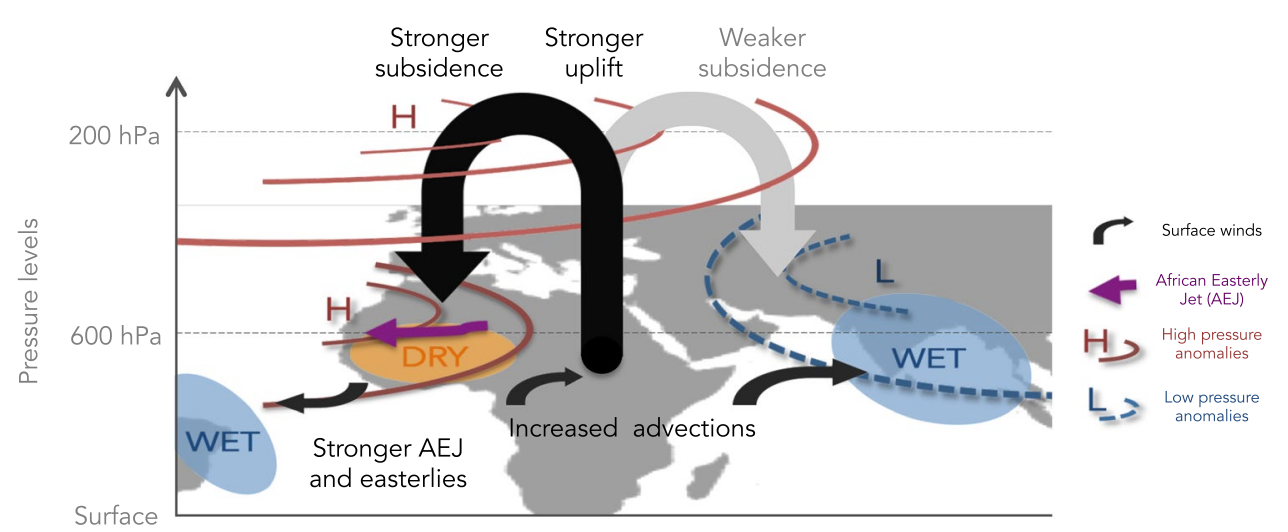

tracks which are similarly spaced (Diedhiou et al. 1999). Core WAM regimes $(3,5$ and 7$)$ are associated with alternating ridge/trough anomalies (Figs. 2 and 7c, e and g) in the wake of which anomalous subsiding/uplift develops, leading to dry/wet rainfall anomalies transiting westwards across the Sahel (Fig. 5c, e and g). One regime (3) is characterized by westerly anomalies over the tropical Atlantic and increased subsidence over the Sahel that resemble Walker circulation anomalies during El Niño translating into dry conditions over the Sahel (Janicot et al. 2001; Lebel et al. 2003). In the late WAM, one regime (regime 4) is related to a trough anomaly along the Atlantic coast off West Africa sustaining moisture advection (Fig. 7d), convection (Fig. 2d) and rainfall (Fig. 5d) over Senegal. For the other regime (regime 6), anomalous ridging inland leads to surface easterly anomalies opposing the monsoon flow towards Guinean regions, where subsiding anomalies (Fig. 7f) and drying prevail (Figs. 2f and 5f). Early and core WAM regimes resemble phases of the Sahel mode and those in the late WAM phases of the QBZD mode, both with the potential for subseasonal predictability including onset predictions (Janicot et al. 2011).

In the early WAM, dry regime 2 is most frequent during MJO phase 6, and both regimes 1 and 2 exhibit highest frequencies when phase 3 leads by 10 days (Fig. 9a, b and h) and convection is enhanced over the Indian Ocean, agreeing with regime 2 teleconnections with the Indian monsoon sector (Figs. 6b, i, 7b). Core WAM regimes 3 and 5 frequencies are increased for MJO phases 1-2 at all leads (Fig. 9c, e), when convection is increased over West Africa (Wheeler and Hendon 2004). Late WAM regimes are more frequent for phases 4-7 at all leads (Fig. 9d, $\mathrm{f}$ and $\mathrm{h}$ ), consistent with the equatorial wave mechanism linked to MJO-induced latent heating anomalies in the warm pool (Lavender and Matthews 2009; Janicot et al. 2011) and skillful week 3-4 precipitation outlooks in phase 7 (Vigaud et al. 2017).

Most wet years coincide with minimum occurrences of regimes 2, 3 and 6, while regimes 2 and 6 are more frequent during dry years (Fig. 10b, c and f). Wet years correspond to increased frequencies of the core WAM wet regime 7
(Fig. 10c, g) characterized by an upward trend towards more frequent occurrences after the 1990 s, which is positively correlated to a global SST warming pattern (Fig. 11g) that agrees with the contribution from climate change to the observed wetting trend in seasonal amounts (Fig. 10h) over the Sahel (Giannini 2015). Potential, but limited North Atlantic controls are evidenced in the early WAM (Fig. 11a, b), and relationships to El Niño and the tropical Atlantic during the core and late WAM (Fig. 11c, d). Teleconnections with Indian Ocean SSTs for the early WAM dry regime 2 further emphasize relationships to the Indian monsoon sector. Overall, the interannual variability of WAM rainfall is well represented by NOAA and ECMWF week-1 regime frequencies (Fig. 12).

ECMWF skill in forecasting regime sequences decreases from week-1 to -4 leads (Fig. 13), with the notable exception of the regime associated with dry spells in the early season (Fig. 14) significantly related to a delay in WAM onset dates (Table 3 and Fig. 15). During early WAM dry spells, ridging anomalies over West Africa strengthen the subsiding branch of the Walker circulation there, the trades and AEJ (not shown) along Guinea Gulf regions, as summarized in the schematic in Fig. 16. Stronger uplift over the East African Rift is fuelled by enhanced advection from the Congo basin, while the subsiding branch of the Walker Asia-Pacific cell is weakened over Asia, where reduced surface divergence favors the southwesterly Indian monsoon flow associated with the Somali jet, consistently with previous studies (Vizy and Cook 2009; Janicot et al. 2011). Such teleconnections, together with relationships to MJO phase 3 more than 10 days in advance, appear as substantial sources of predictability. This agrees with the potential for skillful WAM onset predictions recently evidenced from subseasonal forecasts (Bombardi et al. 2017; Vigaud et al. 2017), here emphasized up to three weeks lead, which is well beyond the predictive capacity of Guinea Gulf rainfall (Fontaine and Louvet 2006). However, the potential for onset prediction using dry regime 2 as a proxy needs to be further tested with regionally defined onset dates (Marteau et al. 
2008; Fitzpatrick et al. 2015, 2016). Contrasts in the relative frequencies of wet regimes 1 and 7 before and after midJune in both NOAA and ECMWF week-1 suggest that these could also help determining onset dates, but both aspects are beyond the scope of this study. Overall, such novel finding could ultimately benefit ongoing prediction efforts, including their application to agricultural planning and food security across the Sahel.

Acknowledgements The authors are grateful to the reviewers whose insightful comments helped improve the manuscript substantially, and to Seydou Traoré and Rémi Cousin for their assistance in computing local onset dates from TAMSAT merged daily rainfall estimates which were accessed from AGRHYMET Data Library (http://crada ta.agrhymet.ne). The authors would like to acknowledge the financial support of the NASA SERVIR AST-2 NNX16AN29G grant as well as the use of forecasts from the S2S database recently published under the WWRP/WCRP S2S project (http://s2sprediction.net). Calculations were performed using IRI resources and S2S subsets archived in the IRI Data Library (IRIDL, http://iridl.ldeo.columbia.edu), from which all other data were

\section{References}

Bombardi R, Pegion K, Kinter J, Cash B, Adams J (2017) Sub-seasonal predictability of the onset and demise of the rainy season over monsoonal regions. Front Environ Sci 5:14. https://doi. org/10.3389/feart2017.00014

Chauvin F, Roehrig R, Lafore J-P (2010) Intraseasonal variability of the Saharan heat low and its link with mid-latitudes. J Clim 23:2544-2561

Cheng X, Wallace J (2003) Regime analysis of the Northern Hemisphere winter-time $500 \mathrm{hPa}$ height field: spatial patterns. J Atmos Sci 50:2674-2696

Diedhiou A, Janice S, Viltard A, de Felice P, Laurent H (1999) Easterly wave regimes and associated convection over West Africa and tropical Atlantic: results from the NCEP/NCAR and ECMWF reanalyses. Clim Dyn 15:795-822

Dinku T, Block P, Sharoff J, Hailemariam K, Osgood D, del Corral J, Cousin R, Thomson M (2014) Bridging critical gaps in climate services and applications in Africa. Earth Perspect 1:15. https:// doi.org/10.1186/2194-6434-1-15

Eltahir E, Gong C (1996) Dynamics of wet and dry years in West Africa. J Clim 9:1030-1042

Fitzpatrick R, Parker D, Marsham J, Knippertz P, Bain C (2015) The West African monsoon onset-a concise comparison of definitions. J Clim 28:8673-8694

Fitzpatrick R, Parker D, Marsham J, Knippertz P, Bain C (2016) On what scale can we predict the agronomic onset of the West African monsoon? Mon Weather Rev 144:1571-1589

Fontaine B, Louvet S (2006) Sudan-Sahel rainfall onset: definition of an objective index, types of years, and experimental hindcasts. J Geophys Res 111(D20103):1-14. https://doi.org/10.1029/2005J D007019

Funk C, Peterson P, Landsfeld M, Pedreros D, Verdin J, Rowland J, Romero B, Husak G, Michaelsen J, Verdin A (2014) A quasiglobal precipitation time-series for drought monitoring. US Geological Survey Data Series 832:4

Funk C, Peterson P, Landsfeld M, Pedreros D, Verdin J, Shukla S, Husak G, Rowland J, Harrison L, Hoell A, Michaelsen J (2015) The climate hazards infrared precipitation with stations-a new environmental record for monitoring extremes. Sci Data 2:150066. https://doi.org/10.1038/sdata.2015.66

Gadgil S, Rajeevan M, Nanjundiah R (2005) Monsoon predictionwhy yet another failure? Curr Sci 88(9):1389-1400

Giannini A (2015) Hydrology: climate change comes to the Sahel. Clim Dyn 18:303-320

Giannini A, Saravanan R, Chang P (2003) Ocean forcing of Sahel rainfall on inter annual to interdecadal time scales. Science 302:1027-1030. https://doi.org/10.1126/science.1089357

Huffman G, Bolvin D (2012) GPCP version 1.2 One-Degree Daily (1DD) precipitation dataset documentation. WDC-A, NCDC, Asheville

Huffman G, Adler R, Morrissey M, Bolvin D, Curtis S, Joyce R, McGavock B, Susskind J (2001) Global precipitation at onedegree daily resolution from multi-satellite observations. J Hydrometeorol 2:36-50

Huffman G, Adler R, Bolvin D, Nelkin E (2010) The TRMM multisatellite precipitation analysis TMPA. In: Chapter 1 in satellite rainfall application for surface hydrology, pp 3-22 Eds Springer Verlag ISBN 978-90-481-2914-0

Janicot S, Moron V, Fontaine B (1996) Sahel droughts and ENSO dynamics. Geophys Res Lett 23:515-518

Janicot S, Trzaska S, Poccard I (2001) Summer Sahel-ENSO teleconnection and decadal time scale SST variations. Clim Dyn 18(3-4):303-320

Janicot S, Mounier F, Hall N, Leroux S, Sultan B, Kiladis G (2009) Dynamics of the West African monsoon. Part IV: analysis of 25-90-day variability of convection and the role of the Indian monsoon. J Clim 22:1541-1565

Janicot S, Mounier F, Gervois S, Sultan B, Kiladis G (2010) Dynamics of the West African monsoon. Part V: the role of convectively coupled equatorial Rossby waves J Clim. https://doi. org/10.1175/2010JCLI3221.1

Janicot S, Caniaux G, Chauvin F, de Coetlogon G, Fontaine B, Hall N, Kiladis G, Lafore J-P, Lavaysse C, Lavender S, Leroux S, Marteau R, Mounier F, Philippon N, Roehrig R, Sultan B, Taylor CM (2011) Intraseasonal variability of the West African monsoon. Atmos Sci Lett 12(1):58-66

Joly M, Voldoire A (2009) Role of the Gulf of Guinea in the inter-annual variability of the West African monsoon: what do we learn from CMIP3 coupled simulations? Int J Clim 30(12):1843-1856

Kanamitsu M, Ebisuzaki W, Woollen J, Yang S-K, Hnilo J, Fiorino M, Potter GL (2002) NCEP-DOE AMIP-2 reanalysis (R-2). Bull Atmos Meteorol Soc 77:1631-1643

Krishna Kumar K, Rajagopalan B, Hoerling M, Bates G, Cane M (2006) Unraveling the mystery of Indian monsoon failure during El Niño. Science 314(5796):115-119

Lavender S, Matthews A (2009) Response of the West African monsoon to the Madden-Julian Oscillation. J Clim 22:4097-4116

Le Barbé L, Lebel T, Tapsoba D (2003) Rainfall variability in West Africa during the years 1950-90. J Clim 15:187-202

Lebel T, Diedhiou A, Laurent H (2003) Seasonal cycle and interannual variability of the sahelian rainfall at hydrological scales, J Geophys Lett. https://doi.org/10.1029/2001JD001580

Liebmann B, Smith C (1996) Description of a complete (interpolated) Outgoing Longwave Radiation dataset. Bull Am Meteorol Soc 83:1631-1643

Livezey R, Chen W (1983) Statistical field significance and its determination by Monte Carlo techniques. Mon Yea Rev 111:46-59

Losada T, Rodriguez-Fonseca B, Janicot S, Gervois S, Chauvin F, Ruti P (2010) A multi-model approach to the Atlantic Equatorial mode: impact on the West African monsoon. Clim Dyn 35(1):29-43

Maidment R, Grimes D, Black E, Tarnavsky E, Young M, Greatrex H, Allan R, Stein T, Nkonde E, Senkunda S, Alcantara E (2017) A new, long-term daily satellite-based rainfall dataset for operational 
monitoring in Africa. Sci Data 4:170063. https://doi.org/10.1038/ sdata.2017.63

Marteau R, Moron V, Philippon N (2008) Spatial coherence of monsoon onset over Western and Central Sahel (1950-2000). J Clim 22:1331-1342

Mathon V, Laurent H, Lebel T (2002) Mesoscale convective system rainfall in the Sahel. J Appl Meteorol 41:1081-1092

Matthews A (2004) Intraseasonal variability over tropical Africa during northern summer. J Clim 17:2427-2440

Michelangeli P, Vautard R, Legras B (1995) Weather regime occurence and quasi-stationarity. J Atmos Sci 52:1237-1256

Moron V, Plaut G (2003) The impact of El Niño-Southern Oscillation upon weather regimes over Europe and the North Atlantic during boreal winter. Int J Climatol 23:363-379

Mounier F, Janicot S, Kiladis G (2008) Dynamics of the West African monsoon. Part III: the quasi-biweekly zonal dipole. J Clim 21:1911-1928

Ramel R, Galle H, Messager C (2006) On the northward shift of the West African monsoon. Clim Dyn 26:429-440

Reynolds RW, Smith TM, Liu C, Chelton D, Casey K, Schlax M (2007) Daily high-resolution-blended analyses for sea surface temperature. J Clim 20:5473-5496

Roebber P (2009) Visualizing multiple measures of forecast quality. Weather Forecast 24:601-608

Rowell D (2013) Simulating SST teleconnections to Africa: What is the state of the art? J Clim 26:5397-5418

Sultan B, Janicot S (2000) Abrupt shift of the ITCZ over West Africa and intra-seasonal variability. Geophys Res Lett 27:3353-3356

Sultan B, Janicot S (2003) Dynamics of the West African monsoon. Part II: the preonset and onset of the summer monsoon. J Clim 16:3407-3427

Sultan B, Janicot S, Diedhiou A (2003) Dynamics of the West African monsoon. Part I: documentation of increased variability. J Clim 1(21):3389-3406

Sultan B, Correia S, Janicot S (2009) Medium-lead prediction of intraseasonal oscillations in West Africa. Weather Forecast 24:767-784

Taylor C (2008) Intraseasonal land-atmosphere coupling in the West African monsoon. J Clim 21:6636-6648

Taylor C, Parker D, Kalthoff N, Gaertner M, Philippon N, Bastin S, Harris P, Boone A, Guichard F, Agusti-Panareda A, Baldi M, Cerlini P, Descroix L, Douville H, Flamant C, Grandpeix J, Polcher J (2011) New perspectives on land-atmosphere feedbacks from the African Monsoon Multidisciplinary Analysis. Atmos Sci Lett $12: 38-44$
Vigaud N, Robertson A (2017) Convection regimes and tropical-midlatitude interactions over the Intra-American Seas from May to November. J Climatol Int 37:987-1000. https://doi.org/10.1002/ joc.5051

Vigaud N, Pohl B, Cretat J (2012) Tropical-temperate interactions over southern Africa simulated by a regional climate model. Dyn Clim 39:2895-2916. https://doi.org/10.1007/s00382-012-1314-3

Vigaud N, Lyon B, Giannini A (2016) Sub-seasonal teleconnections between convection over the Indian Ocean, East African long rains and tropical Pacific surface temperatures. Int J Climatol 3:1167-1180. https://doi.org/10.1002/joc.4765

Vigaud N, Robertson A, Tippett M, Acharya N (2017) Subseasonal predictability of boreal summer monsoon rainfall from ensemble forecasts. Front Environ Sci 5:67. https://doi.org/10.3389/fenvs .2017 .00067

Vigaud N, Ting M, Lee D-E, Barnston A, Kushnir Y (2018) Multiscale variability in North American summer maximum temperatures and modulations from the North Atlantic simulated by an AGCM. J Clim 31:2549-2562

Vitart F, Ardilouze C, Bonet A, Brookshaw A, Chen M, Codorean C, Deque M, Ferranti L, Fucile E, Fuentes M, Hendon H, Hodgson J, Kang H-S, Kumar A, Lin H, Liu G, Liu X, Malguzzi P, Mallas I, Manoussakis M, Mastrangelo D, MacLachlan C, McLean P, Minami A, Mladek R, Nakazawa T, Najm S, Nie Y, Rixen M, Robertson A, Ruti P, Sun C, Takaya Y, Tolstykh M, Venuti F, Waliser D, Woolnough S, Wu T, Won D-J, Xiao H, Zaripov R, Zhang L (2017) The Subseasonal to Seasonal (S2S) prediction project database. Bull Am Meteorol 98:163-173. https://doi.org/10.1175/ BAMS-D-16-0017.1

Vizy E, Cook K (2009) A mechanism for African monsoon breaks: Mediterranean cold air surges. J Geophys Res 114:1-19

Wheeler M, Hendon H (2004) An all-season real-time multivariate MJO index: development of an index for monitoring and prediction. Mon Weather Rev 132:1917-1932

World Meteorological Organization (2013), Sub-seasonal to Seasonal prediction, Geneva

Publisher's Note Springer Nature remains neutral with regard to jurisdictional claims in published maps and institutional affiliations. 